
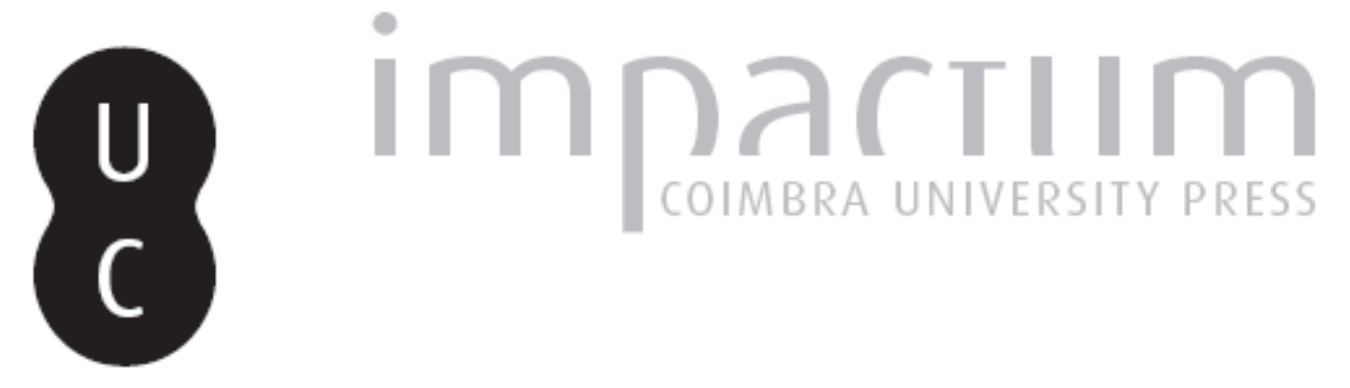

The Parmenides: a dialetheic interpretation

Autor(es): $\quad$ Priest, Graham

Publicado por: Imprensa da Universidade de Coimbra

URL persistente:

URI:http://hdl.handle.net/10316.2/42169

DOI:

DOI:https://doi.org/10.14195/2183-4105_12_3

Accessed : $\quad$ 26-Apr-2023 13:09:02

A navegação consulta e descarregamento dos títulos inseridos nas Bibliotecas Digitais UC Digitalis, UC Pombalina e UC Impactum, pressupõem a aceitação plena e sem reservas dos Termos e Condições de Uso destas Bibliotecas Digitais, disponíveis em https://digitalis.uc.pt/pt-pt/termos.

Conforme exposto nos referidos Termos e Condições de Uso, o descarregamento de títulos de acesso restrito requer uma licença válida de autorização devendo o utilizador aceder ao(s) documento(s) a partir de um endereço de IP da instituição detentora da supramencionada licença.

Ao utilizador é apenas permitido o descarregamento para uso pessoal, pelo que o emprego do(s) título(s) descarregado(s) para outro fim, designadamente comercial, carece de autorização do respetivo autor ou editor da obra.

Na medida em que todas as obras da UC Digitalis se encontram protegidas pelo Código do Direito de Autor e Direitos Conexos e demais legislação aplicável, toda a cópia, parcial ou total, deste documento, nos casos em que é legalmente admitida, deverá conter ou fazer-se acompanhar por este aviso. 
O

Established 1989

$\bigcirc$

$\vdash$

$<$

$\dashv$

ㅇ

-
$Z$
0
-
1
$Z$
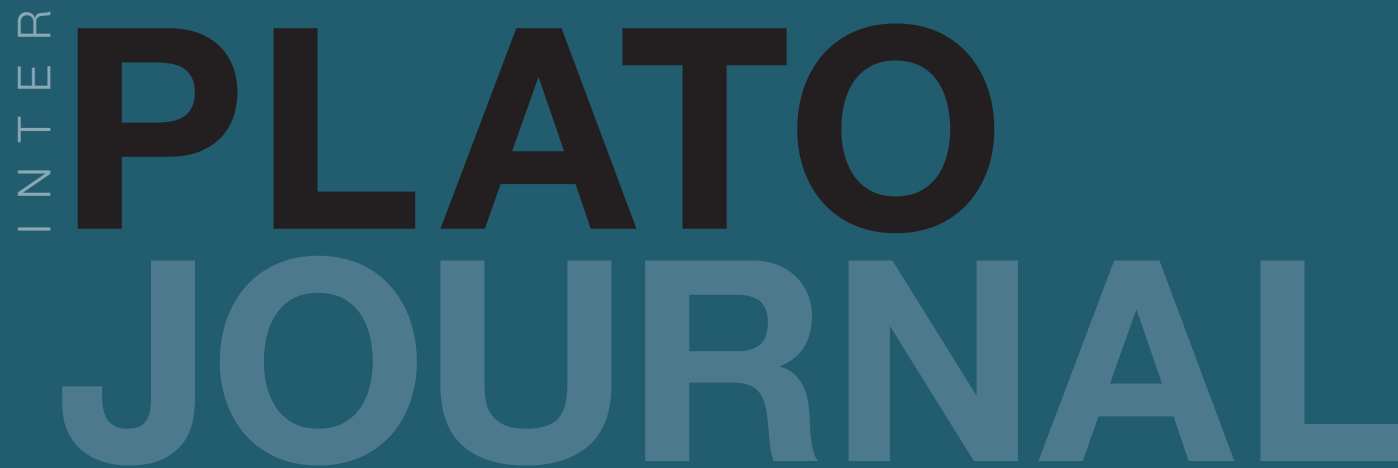

Société Platonicienne Internationale

Associazione Internazionale dei Platonisti

Sociedad Internacional de Platonistas

Internationale

Platon-Gesellschaft 


\title{
The Parmenides: a Dialetheic Interpretation
}

\author{
Graham Priest
}

March 15, 2013

Departments of Philosophy, Universities of Melbourne, St Andrews, and the Graduate Center, City University of New York.

\begin{abstract}
In this paper, I offer a new (dialetheic) interpretation of Plato's Parmenides. The key idea is to take the last speech of the dialogue seriously. The forms indeed have contradictory properties. Defending this idea is what Plato is up to in the second half of the dialogue. And, suitably fleshed out, the idea can be used to answer the objections that Parmenides brings against the theory of forms in the first part.
\end{abstract}

\section{Introduction}

Plato's Parmenides is, as nearly all commentators agree, the most difficult and puzzling of Plato's dialogues - as well as one of the most influential. Gill, for example, says: 'The Parmenides is one of Plato's most important dialogues and without doubt his most enigmatic'. ${ }^{1}$

Many things make it puzzling. For a start, there is the odd fact that although Socrates-Plato's usual mouthpiece - is in the dialogue, he is on the back foot most of the time he is involved, the driver of the dialogue being Parmenides. Next, in the first half of the dialogue, Plato, in the voice of Parmenides, launches an attack on his own theory of forms. It is clear that he

${ }^{1}$ Gill (1996), p. 1; the sentiment is echoed by Miller (1986), p. 1, Scolnicov (2003), p. 1 , and Rickless at the beginning of (2007). 
regards the objections as serious; but he nowhere answers them explicitly - in the Parmenides or elsewhere. Nor does he recant on the theory of forms in any (later) dialogue. ${ }^{2}$ For another, the second half of the dialogue is a relentless sequence of arguments quite unlike anything else in the Platonic corpus. At first glance, it might appear that the two halves of the dialogue have been spliced together accidentally by some compiler. Since this is, it would seem, not the case, one cannot but believe that Plato holds that something about the deductions holds the key to the solution to Parmenides' objections - but what this is, is, to put it mildly, opaque. Fourth, the arguments appear to establish that the one (whatever that is) has a variety of contradictory properties. Indeed the dialogue ends abruptly with the simple endorsement of a contradiction $(166 \mathrm{c}):^{3}$

"Let us say ..., as it seems, whether one is or is not, it and the others both are and are not, and both appear and do not appear all things in all ways, both in relation to themselves and in relation to others."-" "Very true."

So much is agreed by all commentators, but, as Rickless puts it: ${ }^{4}$

Beyond this, there is precious little scholarly consensus. Commentators disagree about the proper way to reconstruct Parmenides' challenges, about the overall logical structure of the Deductions, about the main subject of the Deductions, about the function of the Deductions in relation to the challenges, and about the final philosophical moral of the dialogue as a whole.

The point of this paper is to suggest a new interpretation of the dialogue. The central idea is to take the final conclusion at face value. Plato is indeed suggesting that the one has contradictory properties, and that this is a key to answering Parmenides' arguments.

\footnotetext{
${ }^{2}$ For example, it is employed in the Timaeus, which usual chronologies dates later than the Parmenides. See, e.g., Cherniss (1957).

${ }^{3}$ Translations from the Parmenides are taken from Gill and Ryan (1996).

${ }^{4}$ In the introduction to Rickless (2007).
} 
Such a possibility has never been countenanced before. ${ }^{5}$ This is presumably for two reasons. The first is that dialetheism (the view that some contradictions are true) itself is taken to be manifestly untenable. But dialetheism, whatever one thinks about its truth, is a coherent view with many interesting applications. ${ }^{6}$ The second is that it is implausible to attribute to Plato the possibility of countenancing dialetheism. If this is not just an appeal to the first point, together with the claim that Plato was a sensible fellow, the basis for it is, presumably, the fact that Plato himself appears to endorse a version of the Principle of Non-Contradiction (PNC) in the Republic (436b): ${ }^{7}$

It is obvious that the same thing will never do or suffer opposites in the same respect in relation to the same thing and at the same time.

But little weight can be placed on this, since the Republic is earlier (according to standard chronologies), and Plato, it appears, is being forced to rethink his views in the light of the problems with the theory of forms which he has discovered. ${ }^{8}$ So even if we take it that Plato endorsed the PNC in the Republic, ${ }^{9}$ he may well be arguing against his previous self in the Parmenides. Indeed, on standard chronologies, the Parmenides marks something of a turning point in Plato's dialectical method. After the Parmenides, the earlier method of finding a definition by hypothesis/counter-example/improved hypothesis/counter-example/etc. is replaced in the Sophist and the States-

\footnotetext{
${ }^{5}$ With the notable exception of Hegel (and, according to him, some of the NeoPlatonists - notably Proclus). That the one and the many had contradictory properties was all grist to his dialectical mill. See Haldane and Simson (1995), p. 59 ff.

${ }^{6}$ See Priest (1987), (1997), (2006).

${ }^{7}$ Translation from Hamilton and Cairns (1961). It should be noted, though, that a little later (437a) he calls the Principle an hypothesis, and countenances the possibility that it might turn out to be untenable.

${ }^{8}$ Quite generally, and for the same reason, the method of citing quotations from supposedly earlier dialogues in support of some interpretation of the Parmenides is one that must be used with caution. Whilst it can provide some evidence for the sort of thing that Plato may have been sympathetic to, it cannot be definitive.

${ }^{9}$ One of the problems of the dialogue form is the provisionality of what is said: a view expressed by a character, even Plato's presumed mouthpiece, cannot necessarily be taken to represent his considered opinion.
} 
man with the method of finding a definition by iterated subdivision of categories. It should be remembered, also, that Plato is writing before Aristotle's attack on dialetheism in the Metaphysics, the attack which firmly locked the PNC into Western philosophical orthodoxy.

Next on preliminary matters, an important word on the methodology adopted in this essay. Beyond the prophylactic comments of the last paragraph, I shall have nothing to say here about the relationship of the Parmenides to the other texts in the Platonic corpus. The Parmenides, it seems to me, has a certain integrity; and my aim is to let the text speak for itself. ${ }^{10}$

Of course, the relationship between the text and the rest of the Platonic corpus is an important scholarly question. Crucially, one may ask, how does the Parmenides, on my account, relate to the works generally taken to be later? Does the view which I shall attribute to Plato inform these, or was it just something that Plato tried out, and quietly gave up? ${ }^{11}$ I am content to leave such questions to scholars who are much better placed to address them than I.

A few final comments to help orient the reader to what is to come. I shall start by explaining a certain (dialetheic) theory of forms and participation. I will then proceed, in the bulk of the paper, by way a commentary on the text. In the final section of the paper I will stand back and look at the whole.

The commentary I shall give is not intended to be a scholarly one. I am not qualified for such an undertaking. ${ }^{12}$ The point of the commentary is to show how many puzzling features of the text make sense from the perspective of the theory of forms in question - though I make no claim to explain every one of its puzzling features. ${ }^{13}$ Indeed, that so many such features fall into

\footnotetext{
${ }^{10}$ Plato, it would seem, loves to play with ideas. He clearly runs incompatible lines in different dialogues - to take an obvious example: in the Phaedo it is crucial that the soul is simple; in the Republic, it is crucial that it is not. Arguably, one should understand the integrity of each text before worrying about how they do or do not fit together.

${ }^{11}$ There are also important questions about the interpretation and texts outside the Platonic corpus. If Plato at least played with the idea of contradictory forms, why did not Aristotle mention Plato in his attack on dialetheism in the Metaphysics? Was he, perhaps, just as puzzled by the Parmenides as the rest of us are?

${ }^{12}$ There are many such commentaries. Gill (1996) is one dependable one.

${ }^{13}$ I wonder whether Plato himself could have done this. Creators of literary works are not always able to explain, themselves, exactly why they put particular features into them.
} 
place is the fact that speaks most strongly in favour of the interpretation I shall offer. However, I shall make no serious attempt to describe other possible interpretations of the text, or to argue that the interpretation I suggest is preferable. That would require an inordinately longer and more scholarly work than this. ${ }^{14}$ The point of the present article is simply to put a certain interpretation of the Parmenides into play, and show its plausibility. ${ }^{15}$

\section{Unity and Participation}

Before we turn to the commentary, I need to say something about the view which informs it. This is an account of the nature of forms (and maybe, more generally, of universals) and the participation relation. This account, in turn, depends on a view about the nature of unity. So let me start by describing that. I shall not attempt to justify it here, or to show its technical coherence. This is done elsewhere. ${ }^{16}$ I merely wish to explain the essence of the view in question.

Take an object with parts. What makes them into a single thing? There must be something in virtue of which they form a unity. Quite possibly, the kind of this thing depends on the unity in question. If the unity is a house, its parts are bricks, and maybe what makes them into a unity is their

\footnotetext{
${ }^{14}$ Rickless (2007) provides an admirable account of the various interpretations of the text which have so far been offered, with some attempts to adjudicate.

${ }^{15}$ I have been helped in thinking through the issues the text poses by various seminars on the Parmenides that I have run over the last few years. The most important of these were two series of seminars run jointly by Sarah Brodie and myself in St Andrews, in 2007 and 2009. I would like to thank all those who have struggled with me through the text, helping to illuminate the dark material, but especially to Sarah herself, for her perceptive comments and her sympathetic encouragement. In this connection, special thanks also go to Amber Carpenter, Theodore Scaltsas, and Elia Zardini. Thanks, too, go to Maureen Eckert for discussions which helped illuminate a number of matters, and to Verity Harte and Christof Rapp for comments on a written draft of the paper. Last, but by no means least, thanks go to an anonymous referee from this journal. The first, and hardest, draft of the paper was written when I was a visiting professor at the Graduate Faculty of Letters, Kyoto University in 2008. My thanks go to my hosts there, and especially to Yasuo Deguchi, for their warm hospitality.

${ }^{16}$ See Priest $(201+)$.
} 
geometric configuration. If the unity is a symphony, its parts are notes, and maybe what makes them into a unity is their arrangement. But whatever the binding agent is, there must be one. Let us call it, neutrally, the gluon of the unity. As soon as one starts to think about gluons, they appear to have contradictory properties. A gluon is an object: we can think about it, quantify over it, refer to it. But it is not an object: if it were, the totality comprising it and the other parts would be just as much a plurality as the parts themselves, and we would want for an explanation of how the unity is achieved. Think of Bradley's regress at this point. If the gluon were just another object, there would need to be a "hypergluon", holding the gluon and the other parts together. And so on... The contradictory nature of gluons surfaces from time to time in the history of philosophy. One place is in Frege's discussion of concepts. Concepts are the gluons of propositions. They hold them together in virtue of the fact that they are "unsaturated". In consequence of their unsaturatedness, they are not objects. But the concept is a horse (to use Frege's own example) is an object, since it is referred to by that very definite description. ${ }^{17}$

Next, how is it that the gluon holds all the parts (including itself) together? If it were distinct from the other parts, Bradley's regress would strike. A way to avoid this is to take the gluon to be identical with each of the other parts. How to make sense of this idea? We may define identity in the standard fashion, deploying Leibniz' identity of indiscernibles: $x=y$ is $\forall Z(Z x \equiv Z y)$, where the quantifier is second-order, and the connective is the material biconditional. Note, however, that we are dealing with objects some of which are contradictory. Hence this must be the material biconditional of some paraconsistent logic. ${ }^{18}$ So suppose that we have a unity; let its gluon be $g$, and let $a, b, c$ and $d$ be its (other) parts. Then $g=a, g=b, g=c$,

\footnotetext{
${ }^{17}$ See Priest (1995), 12.1, 12.2.

${ }^{18} \mathrm{~A}$ paraconsistent logic one in which an arbitrary contradiction does not imply an arbitrary conclusion, as it is said to do so in standard contemporary logic textbooks. There are, in fact, many paraconsistent logics, with significant differences between them-which are mostly not relevant here. For a very simple introduction to paraconsistency, see Priest (1998), and for a longer introduction, see Priest and Tanaka (2009).
} 
and $g=d$ :

$$
a=\begin{aligned}
& d \\
& \| \\
& \| \\
& b
\end{aligned}=c
$$

We can insure that the identities hold by taking $g$ to have all the properties of $a, b, c$ and $d$. Naturally, since the parts are liable to have a variety of disparate properties, $g$ is liable to be a contradictory object-but we knew that already. Note, also, that in virtually all paraconsistent logics, the material biconditional is not transitive: $A \equiv B, B \equiv C \nvdash A \equiv C$. So the fact that $a=g$ and $g=b$ does not entail that $a=b$. The various parts are not, generally speaking, identical.

For a very simple illustration of how this all works, suppose that the parts are just $a, b$, and $g$, and that there is only one property at issue, $P$. Suppose that (consistently) $P a, \neg P b$, but that $P g \wedge \neg P g$. Then $P a \equiv P g$ and $P g \equiv P b,{ }^{19}$ but it is not the case that $P a \equiv P b$. Hence (since $P$ is the only property at issue), $a=g, g=b$, but it is not the case that $a=b$.

So much for the theory of unity, of gluons, and identity. Let us now apply it to forms and participation. Given an object, $a$, consider its tropes: $a$ 's redness, a's heaviness, a's roundness, etc. ${ }^{20}$ Now, take a bunch of, say, red things, $a, b, c, \ldots$ Consider $a$ 's redness, $b$ 's redness, etc. One can think of these as the parts a single totality. (They have a unity in a way that the redness of $a$, the roundness of $b$, the heaviness of $c$, do not.) What unifies them is the gluon of this totality, and this, it is natural to suppose, is redness itself: what it is that makes them the same thing - red. Thus, we have the

\footnotetext{
${ }^{19}$ And also $\neg(P a \equiv P g)$ and $\neg(P g \equiv P b)$.

${ }^{20} \mathrm{We}$ can, if we wish, think of the totality of these parts as $a$ itself, as in standard trope theory. (See, e.g., Bacon (1995).)
} 
following picture. $r$ is redness itself, and $r_{x}$ is $x$ 's redness.

$$
\begin{aligned}
& r_{d} \\
& \text { II } \\
& r_{a}=r=r_{c} \\
& \text { II } \\
& r_{b}
\end{aligned}
$$

An understanding of the participation relation naturally follows. $a$ is red just if its redness is identical to redness itself. More precisely, for $a$ to participate in the form of $F$-ness is exactly for it to have a trope (the $F$-part of $a$ ) which is identical with $F$-ness, as follows. (The crosses are $a$ 's other tropes.)

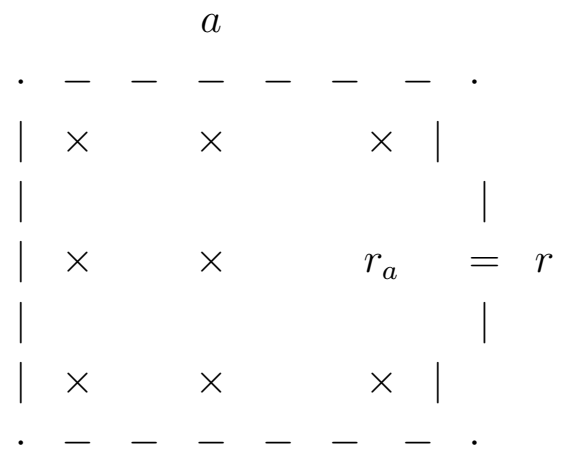

It follows that the universal of $F$-ness will have every property possessed by the $F$-trope of every $x$ that has one. This is, indeed, the way that it manages to be identical with each of these $F$-tropes. It will therefore be an inconsistent object.

So much for the theory of universals and instantiation which provides the backdrop to the commentary. Let us now turn to this.

\section{The Reply to Zeno (126a-130a)}

After a brief stage-setting, the dialogue starts just after Zeno has finished reading his book. It is established that the content of the book is a defence of Parmenides' view that what is is one thing. Many had objected to Parmenides' view that it had contradictory consequences. Zeno's tract attempts to 'pay them back in kind' (128d), by showing that the view that there is a 
multitude of things entails contradictions, such as that these things are like and unlike, one and many, and so on. ${ }^{21}$

Socrates then responds at length (129a-130a):

"But tell me this: don't you acknowledge that there is a form, itself by itself, of likeness, and another form, opposite to this, which is what unlike is. Don't you and I and the other things we call 'many' get a share of those two entities? And don't things that get a share of likeness come to be like in that way and to the extent that they get a share, whereas things that get a share of unlikeness come to be unlike, and that things that get a share of both come to be both? And even if all things get a share of both, though they are opposites, and by partaking of them are both like and unlike themselves, what's astonishing about that?

If someone showed that the likes themselves come to be unlike or the unlikes like - that, I think, would be a marvel; but if he shows that things that partake of both of these have both properties, then there seems to me to be nothing strange about that, Zenonot even if someone shows that all things are one by partaking of oneness, and these same things are many by partaking also of multitude. But if he should demonstrate this thing itself, what one is, to be many, or conversely, that many to be one - at this I'll be astonished.

And it's the same with all the others: if he could show that the kinds and forms themselves have in themselves opposite properties, that would call for astonishment. But if someone should demonstrate that I am one thing and many, what's astonishing about that? He will say, when he wants to show that I am many, that my right side is different from my left, and likewise with my upper and lower parts - since I take it I do partake of multitude.

\footnotetext{
${ }^{21}$ According to Proclus, Zeno's book contained 40 arguments, each one deriving some contradiction from the hypothesis that there is a multitude of things. The only argument that we have left is reported by Simplicius, and is to the effect that if there are many things, each is both limited and unlimited. See Gill (1996), p. 11.
} 
But when he wants to show that I'm one, he will say that I'm one person among seven of us, because I also partake of oneness. Thus he shows that both are true.

So if - in the case of sticks and stones and such things - someone tries to show that the same thing is many and one, we'll say that he is demonstrating something to be many and one, not the one to be many or the many to one - and we'll say that he is saying nothing astonishing, but just what all of us would agree to. But if someone first distinguishes as separate the forms, themselves by themselves, of the things I was talking about a moment agofor example, likeness and unlikeness, multitude and oneness, rest and motion, and everything of that sort - and then shows that in themselves they can mix together and separate, I for my part," he said, "would be utterly amazed, Zeno. I think these issues have been handled with great vigour in your book; but I would, as I say, be much more impressed if someone were able to display this same difficulty, which you and Parmenides went through in the case of visible things, also similarly entwined in multifarious ways in the forms themselves - in things that are grasped by reason."

Three things are clear about this speech. The first is that the theory of forms is mooted. There are forms, separate from physical objects, and something is $F$ iff (if and only if) it partakes in ('gets a share of') the form of $F$-ness. The second is that Socrates says that it is not at all puzzling that physical objects can partake of contradictory forms. The third we will come to in a second.

Two reasons - not clearly separated - are given as to why it is unsurprising that physical objects may be $F$ and not- $F$. One (in the third paragraph), which does not involve the theory of forms, is to the effect that the object may be $F$ in one respect, and not- $F$ in another: I am a multitude of bodily parts, but one person; or I am like my mother but unlike my father, etc. In other words, the property $F$ is under-specified, and once one makes a complete specification, the contradiction disappears. This cannot be all there is to the matter, however. If it were, there would be no need for the theory of forms 
to be mentioned here at all; nor would there be anything surprising in the fact that the forms themselves could appear to be contradictory in exactly the same way that physical objects are. One may suppose, then, that Plato must think that there are cases in which the $F$ in question is taken to be completely specified. It may be, for example, that an object is one object of a certain kind, and many objects of the same kind. Or it may be that an object is both at rest and in motion, where these are absolute, not relative to anything. (Of course, we are now used to thinking that motion is relative - to a frame of reference; but this is with two millennia of science after Plato.)

The second reason why it is not surprising that physical objects have contradictory properties (first paragraph) does involve the theory of forms, and is something, I guess, like this. If $P x$ is some predicate, let us write $\bar{P} x$ for its contradictory (opposite). Let us write $\pi x P x$ for the form of $P$-ness, and $\rightarrow$ for 'participates in'. Then, the apparent contradiction:

(0) $P y \wedge \bar{P} y$

is really of the form:

(1) $y \rightarrow \pi x P x \wedge y \rightarrow \pi x \bar{P} x$

which is 'not surprising' - presumably, since this is not a contradiction.

If this is the reason, it is not a very good one. Plato is committed to the view that what makes something $P$ is precisely its participation in the form of $P$-ness:

(2) $P y$ iff $y \rightarrow \pi x P x$

For future reference, call (2) the Grounding Principle (since participation in the forms grounds the truth of the predication). Given this, (1) is not a replacement for the contradiction; it is equivalent to it. What we have here is an explanation for the contradiction, not a defusing of it. ${ }^{22}$

If the forms themselves turned out to be contradictory, could a similar explanation be attempted? Perhaps, if forms can themselves partake of forms. But Plato is quite clear that the forms are not contradictory. This is, indeed,

\footnotetext{
${ }^{22}$ Indeed, (0), (2), and contraposition, immediately give that $(y \rightarrow \pi x P x) \wedge \neg(y \rightarrow$ $\pi x P x)$.
} 
the third thing that is clear from the speech: Socrates is adamant that the forms are not contradictory in the same way that physical objects may be. If $f$ is a form, there can be no predicate, $P x$, completely specifying a property, such that $\operatorname{Pf} \wedge \bar{P} f$.

Note that (in the second and fourth paragraphs) Socrates shows special interest in whether or not a form can have its opposite property, whether the like can be unlike, or unity can be many - whether, that is, it can be the case that:

(3) $\bar{P} \pi x P x$

Since he clearly takes this to be a contradiction, it must be because he is assuming that the form must have its own property: the like is like, the one is one:

(4) $P \pi x P x$

For future reference, let us call (4) Self-Predication. To establish that $\bar{P} \pi x P x$ would, then, be the most direct way of establishing that a form could have contradictory properties. Thus, Socrates appears to be committed to the thought that we always have (4), and never (3).

At any rate, the upshot of all this is that Socrates has laid down a challenge: to show that the forms are contradictory in exactly the way that physical objects are - and it is exactly this which is admitted to have been shown at the end of the dialogue. The forms are indeed contradictory.

\section{Parmenides' Attack, 1 (130a-131e)}

At this point, Parmenides enters the debate. Parmenides gets Socrates to confirm his picture of the forms (130b). Then, after some banter about exactly what forms there are, he launches into an attack on the theory.

The first objection starts as follows (130e-131b):

"But tell me this: is it your view that, as you say, there are certain forms from which these other things, by getting a share of them, derive their names - as, for instance, they come to be like by 
getting a share of likeness, large by getting a share of largeness, and just and beautiful by getting a share of justice and beauty?" "It certainly is," Socrates replied.

"So does each thing that gets a share get as its share the form as a whole or part of it? Or could there be some other means of getting a share apart from these two?"

"How could there be?" he said.

"Do you think, then, that the form as a whole - one thing - is in each of the many? Or what do you think?

"What's to prevent it from being one, Parmenides?" said Socrates.

"So, being one and the same, it will be at the same time, as a whole, in things that are many and separate; and thus it would be separate from itself."

Parmenides has offered Socrates a choice: does something that is $F$ partake in the whole of $F$-ness or just a part of it? Socrates tentatively accepts the first possibility, and Parmenides then points out that the whole form would then be 'in things that are many and separate'. Socrates objects (131b-131c):

"No it wouldn't," Socrates said. "Not if it's like one and the same day. That is in many places at the same time and is none the less not separate from itself. If it's like that, each of the forms might be, at the same time, one and the same in all."

"Socrates" he said, "how neatly you make one and the same thing be in many places at the same time! It's as if you were to cover many people with a sail, and then say that one thing as a whole is over many. Or isn't that the sort of thing you mean to say?"

"Perhaps," he replied.

"In that case, would the sail be, as a whole, over each person, or would part of it be over one person and another part over another?

"A part." 
"So the forms themselves are divisible, Socrates," he said, "and things that partake of them would partake of a part; no longer would a whole form, but only a part of it, be in each thing."

"It does appear in that way."

Socrates has offered a way in which the whole of something might be in different places. Parmenides argues that it is only part of the thing in each place, and so we really have the second of the alternatives that Socrates was offered. He then goes on to attack this (131c-131e):

"Then are you willing to say, Socrates, that our one form is really divided? Will it still be one?"

"Not at all," he replied.

"No," said Parmenides. "For suppose that you are going to divide largeness itself. If each of the many things is to be large by a part of the largeness smaller than largeness itself, won't that appear unreasonable?"

"It certainly will," he replied.

"What about this? Will each thing that has received a small part of the equal have something by which to be equal to anything, when its portion is less than equal itself?"

"That's impossible."

"Well, suppose one of us is going to have a part of the small. The small will be larger than a part of it, since the part is a part of it: so the small itself will be larger! And that to which the part subtracted is added will be smaller, not larger, than it was before."

"That surely couldn't happen," he said.

"Socrates, in what way, then, will the other things get a share of your forms, if it can do so neither by getting parts nor by getting wholes?"

"By Zeus!" Socrates exclaimed. "It strikes me that's not at all easy to determine." 
Parmenides points out a number of supposedly absurd consequences of the possibility that something is $F$ by partaking of part of $F$-ness; and Socrates is floored.

There is much that could be said about this argument - and much that has been said. One could balk at virtually every one of Parmenides' arguments. But for present purposes, we do not need to dissect the dialectic in detail. The question is how, armed with the theory of forms proposed here, we should deal with Parmenides' objections.

To address this, let us start by asking what, exactly, a part of a form is. The only natural answer is that the parts of $F$-ness are $a$ 's $F$-ness, b's $F$-ness, etc., where $a, b, \ldots$ are the $F$-objects. But this is not correct. $F$-ness itself is, according to our account, the gluon of the whole comprising these tropes. Given this, it is not at all clear in what sense $F$-ness might have proper parts, or, therefore, in what sense something can get a share of one. In this case, we are left with the other alternative: an $F$-object participates in a form by sharing all of it, or just it itself. In a similar way, when we say that 0 is a member of the set $\{0,1,2\}$, we are saying that 0 is a member of the whole set. It may be a member of a part $(0 \in\{0,1\})$, or it may not $(0 \notin\{1,2\})$. These are different matters.

The problem we face is, then, the one posed by the first horn of Parmenides' dilemma. This was how the form, as a whole, is in 'things that are many and separate' and thus 'separate from itself'. The objection could be interpreted in a number of ways, but the most obvious is simply as an objection to the effect that something cannot be (completely) in more than one place at the same time; that were a contradiction. ${ }^{23}$ So be it: the form is a contradictory object. But note that this is by no means the ad hoc acceptance of a contradiction. The contradiction in question is exactly one that the theory of forms at hand delivers. According to this theory, the form of $F$-ness, that gluon, has all the properties possessed by the $F$-ness of any object which is $F$. That is, indeed, how it manages to be identical with it.

\footnotetext{
${ }^{23}$ One might suggest that the absurdity involved is that if the form can be completely in different objects, then it has parts, and so is not a unity. But it seems clear that a unity can have parts. It is a simplex that cannot have parts. The thought that a form is a simplex has not been raised at this stage of the dialogue.
} 
Now, suppose that I am red. My redness is located where I am; it moves with me; it is not located somewhere else. (Similarly for my shape, my beauty (hrmph), and so on: these things are located where I am, and nowhere else.) But suppose that you are red too; then your redness is located where you are, and nowhere else. So redness itself is located where I am, and nowhere else, and where you are, and nowhere else. It is wholly present at both places.

\section{Parmenides' Attack, 2 (132a-133a)}

Parmenides' next argument is a regress argument, later to be dubbed the "Third Man Argument" by Aristotle (e.g., Metaphysics 990 $\left.17-1079^{a} 13\right)$. Parmenides begins as follows (132a-132b):

"I suppose that you think that each form is one on the following ground: whenever some number of things seem to you to be large, perhaps there seems to be some one character, the same as you look at all of them, and from that you conclude that the large is one."

"That's true," he said.

"What about the large itself, and the other large things? If you look at them all in the same way with the mind's eye, again won't some one thing appear large, by which all these appear large?"

"It seems so."

"So another form of largeness will make its appearance, which has emerged alongside largeness itself and the other things that partake of it, and in turn another over all these, by which all of them will be large. Each of your forms will no longer be one, but unlimited in number."

Parmenides argues that there is not a unique form by virtue of participation in which things are large, contradicting the Grounding Principle. Largeness of course, is just an example. It could be any other form. Socrates replies $(132 \mathrm{~b}-132 \mathrm{c})$ : 
"But, Parmenides, maybe each of these forms is a thought," Socrates said, "and properly occurs in minds. In that way each of them might be one and no longer face the difficulties mentioned just now."

"What do you mean?" he asked. "Is each of the thoughts one, but a thought of nothing?"

"No, that's impossible," he said.

"Of something, rather?"

"Yes."

"Of something that is, or of something that is not?"

"Of something that is."

"Isn't it of some one thing, which that thought thinks is over all the instances, being some one character?"

"Yes."

"Then won't this thing that is thought to be one, being the same over all instances, be a form?"

"That, too, appears necessary."

"And what about this?" said Parmenides. "Given your claim that other things partake of these forms, won't you necessarily think either that each thing is composed of thoughts and all things think, or that, although they are thoughts, they are unthinking?"

Socrates' reply appears to miss the point. Parmenides' argument is not affected by whether the form is within the mind or without it. ${ }^{24}$ The argument makes no assumptions on this score. But Parmenides ignores this, and attacks the claim that forms are in the mind. Parmenides' reply is itself confused. For a start, Socrates has said that the form is a thought, but Parmenides takes him to be talking of a thought of form. And the final coup

\footnotetext{
${ }^{24}$ Maybe the idea is that if forms are in the mind then Self-Predication is false (and we are not required to hold that largeness itself is large), since thoughts apply only to things outside the mind. But if this is the idea, it won't get very far. Clearly, thoughts can be of thoughts; and 'the thoughts I have had today' applies to that very thought.
} 
de grâce is a complete non-sequitur. ${ }^{25}$ Still, it is enough to force Socrates to recant. He continues (132c-133a):

"That isn't reasonable either, Parmenides," he said. "No, what appears to me most likely is this: these forms are patterns set in nature, and other things resemble them and are likenesses; and this partaking of the form is, for the others, simply being modelled on them."

"If something resembles the form," he said, "can that form not be like what has been modelled on it, to the extent that the thing has been made like it? Or is there any way for something like to be like what is not like it?"

"There is not."

"And isn't there a compelling necessity for that which is like to partake of the same one form as what is like it?"

"There is."

"But if like things are like by partaking of something, won't that be the form itself?"

"Undoubtedly."

"Therefore, nothing can be like the form, nor can the form be like anything else. Otherwise, alongside the form another form will always make its appearance, and if that form is like anything, yet another, and if the form proves to be like what partakes of it, a fresh form will never cease to emerge."

"That's very true."

"So other things don't get a share of the form by likeness; we must seek some other means by which they get a share."

"So it seems."

Socrates moots the idea that participation is likeness, but this does not help. Either forms are not like their instances, so Socrates is wrong; or, more

\footnotetext{
${ }^{25}$ For some way of making sense of the whole passage, see Gill (1996), pp 38-42.
} 
plausibly, they are like their instances (as Parmenides argues), and the regress strikes anyway. ${ }^{26}$

Perhaps even more has been written about this argument than about the previous one; and one might, again, question many of the assumptions packed into it. But the crucial question here is whether one can solve the regress problem which Parmenides raises on the model of forms and participation on the agenda here, and if so how.

Consider a bunch of large things, say $a, b$, and $c$. According to the theory of forms, each is large by participating in largeness. So we have:

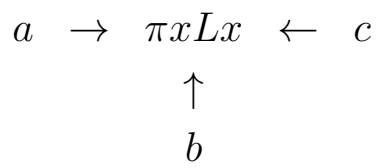

If the form of largeness could participate in itself, we would have:

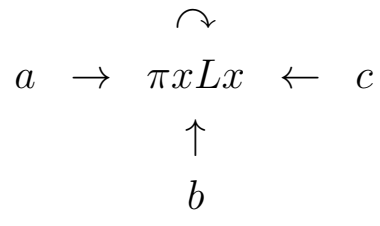

The regress argument assumes, without explicit argument, that this cannot happen, that the arrow of participation cannot be reflexive. So largeness itself (and the other large things) must participate in a different form, and we are off on the regress. If it stopped at some stage, then there would be a "highest" form that all large things participated in. But it does not.

But why does Socrates agree to the irreflexivity assumption? For the answer, look to Parmenides' summary of the theory of forms, to which Socrates agrees, at the start of the first argument (130b):

"Tell me. Have you yourself distinguished as separate, in the way you mention, certain forms themselves, and also as separate the things that partake of them? And do you think that likeness itself is something, separate from the likeness we have? And one and many and all the things you heard Zeno read about a while ago?'

\footnotetext{
${ }^{26}$ Some commentators take this part of the text to establish a regress specifically about the form of likeness. This strikes me as a less plausible interpretation.
} 
"I do indeed," Socrates answered.

Socrates takes the forms to be separate from the things that instantiate them. A form, then, cannot be identical to any of its instances.

On the theory of forms at hand, however, largeness itself may be distinct from all its instances, and so itself; but that does not rule out largeness itself being identical with itself as well, and so identical to one of its own instances! And if largeness is, indeed, one of its own instances, as Self-Predication plus the Grounding Principle tell us, the regress is broken.

Indeed, that the form is both identical to and different from itself is exactly a consequence of the theory of forms at hand. Everything is identical with itself, $x=x$ : that is a logical truth $-\forall Z(Z x \equiv Z x)$. But the properties of largeness itself are the properties of the largeness of $a$, the largeness of $b$, etc. Now the largeness of $a$ is distinct from the largeness of $b$. Hence largeness itself is distinct from the largeness of $b$; and so again, largeness itself is distinct from largeness itself. ${ }^{27}$

One may fairly ask whether Self-Predication is true on the present account. According to this account, what it is for the form, $P$, to instantiate itself? It is for it to have a trope, the $P$-ness of $P$, which is identical to $P$. What is the $P$-ness of $P$ ? The most obvious suggestion is $P$ itself, which is certainly identical to $P{ }^{28}$

\section{Parmenides' Attack, 3 (133b-135b)}

Parmenides' third attack is, it seems to me, the hardest to understand. It has two parts. In the first, Parmenides appears to argue that the forms cannot be known (by us) (133b-134b):

"... I think that you, Socrates, and anyone else who posits that there is for each thing some being, itself by itself, would agree, to begin with, that none of those beings is in us."

\footnotetext{
${ }^{27}$ Or again, there is some predicate, $P$, such that the largeness of $a$ satisfies $P$, and the largeness of $b$ satisfies not- $P$. Hence, largeness itself, $l$, satisfies both $P$ and not- $P$. It follows that $\neg(P l \equiv P l)$, and hence that $\neg \forall Z(Z l \equiv Z l)$.

${ }^{28}$ Note, also, that if a form instantiates itself, there are no empty forms.
} 
"Yes - how could it still be itself by itself?" replied Socrates.

"Very good," said Parmenides. "And so all the characters that are what they are in relation to each other have their being in relation to themselves but not in relation to things that belong to us. And whether one posits these as likenesses or in some other way, it is by partaking of them that we come to be called by their various names. ${ }^{29}$ These things that belong to us, although they could have the same names as the forms, are in their turn what they are in relation to themselves but not in relation to the forms; and all the things named in this way are of themselves but not of the forms."

"What do you mean?" Socrates asked.

What indeed?!

"Take an example," said Parmenides. "If one of us is somebody's master or somebody's slave, he is surely not a slave of master itself - of what master is - nor is the master a master of slave itself - of what slave is. On the contrary, being a human being, he is a master or a slave of a human being. Master itself, on the other hand, is what it is of slavery itself. Things in us do not have their power in relation to forms, nor do they have theirs in relation to us; but, I repeat, forms are what they are of themselves and in relation to themselves, and things that belong to us are, in the same way, what they are in relation to themselves. You do understand what I mean?"

"Certainly," said Socrates, "I understand."

"So too," he said, "knowledge itself, what knowledge is, would be knowledge of the truth itself, which is what truth is?"

\footnotetext{
${ }^{29}$ Cornford translates these two sentences, somewhat more intelligibly, as 'And further, those forms which are what they are with reference to one another have their beings in such references among themselves, not with reference to those likenesses, or whatever we are to call them, in our world, which we possess and so come to be called by their several names' (Hamilton and Cairns (1961)).
} 


\section{"Certainly."}

"Furthermore, each particular knowledge, what it is, would be knowledge of some particular thing, of what that thing is. Isn't that so?"

"Yes."

"But wouldn't knowledge that belongs to us be of the truth that belongs to our world? And wouldn't it follow that each particular knowledge that belongs to us is in turn knowledge of some particular thing in our world?"

"Necessarily."

"But, as you agree, we neither have these forms themselves nor can they belong to us."

"Yes, you are quite right."

"And surely the kinds themselves, what each of them is, are known by the form of knowledge itself."

"Yes."

"The very thing we don't have."

"No, we don't."

"So none of the forms is known by us, because we don't partake of knowledge itself."

"It seems not."

"Then the beautiful itself, what it is, cannot be known by us, nor can the good, nor, indeed, can any of the things we take to be characters in themselves."

"It looks that way."

The second part of Parmenides' argument is to the effect that, for symmetric reasons, the gods cannot know of us and our affairs (134b-134e):

"Here's something even more shocking than that."

"What's that?" 
"Surely you would say that if in fact there is knowledge - a kind itself-it is much more precise than knowledge that belongs to us. And the same goes for beauty and all the others."

"Yes."

"Well, whatever else partakes of knowledge itself, wouldn't you say that god more than anyone else has this most precise knowledge?"

"Necessarily."

"Tell me, will god, having knowledge itself, then be able to know things that belong to this world?"

"Yes, why not?"

"Because we have agreed, Socrates," Parmenides said, "that those forms do not have their power in relation to things in our world, and things in our world do not have theirs in relation to the forms, but that things in each group have their power in relation to themselves."

"Yes, we did agree that."

"Well then, if this most precise mastery and the most precise knowledge belong to the divine, the gods' mastery could never master us, nor could their knowledge know us or anything that belongs to us. No, just as we do not govern them by our governance and know nothing of the divine by our knowledge, so they in their turn are, for the same reason, neither our master nor, being gods, do they know human affairs.

"If god is to be stripped of knowing," he said, "our argument may be getting too bizarre."

Parmenides' point is the following. There are, it has been agreed, two kinds of things, the visibles and the intelligibles; and if a relation holds between two things, both the relation and the relata must be of the same kind. ${ }^{30}$ Thus,

\footnotetext{
${ }^{30}$ It might be suggested that it is only definitional relations which require this. But that cannot be the argument. For it is applied to our knowledge of the forms, and the gods' knowledge of us. These are not definitional matters.
} 
if we know something, the knowledge must be of a mundane kind, as must the object of our knowledge. And if something knows the forms, both the knower and the relationship must be of the same kind, the relationship being knowledge itself, and the knower being (a) god. There can be no cross-kind relations. Hence we cannot have any kind of knowledge-relation to the forms, and god cannot bear any kind of knowledge-relation to us.

The main problem with this argument is to see why Socrates finds it to be a problem. The claim that there cannot be cross-kind relations seems to be based entirely on generalising the master/slave example. Of course, the relation between a master and a slave is between things of the same kind. But it is hardly the case that all relations are like this. Participation relations, such as that between red things and the form of redness clearly seem quite different; and a knowledge-relation between us and the forms is of the same kind.

The key here, perhaps, is the way that Parmenides actually introduces the argument, a paragraph I omitted (133b):

"There are many reasons [why it is difficult to maintain the theory of forms]," Parmenides said, "but the main one is this: suppose someone were to say that if the forms are such as we claim they must be, they cannot even be known. If anyone should raise this objection, you wouldn't be able to show that he is wrong, unless the objector happened to be widely experienced and not ungifted, and consented to pay attention while in your effort to show him you dealt with many distant considerations. Otherwise, the person who insists that they are necessarily unknowable would remain unconvinced."

Parmenides does not claim to show that the forms are unknowable. What he claims is that if someone were to say that the forms are unknowable, it would be very hard to show otherwise. Perhaps, then, the point of Parmenides' arguments is to throw down a challenge as to how one should understand cross-kind relations, participation being a paradigm of these. Socrates is at a loss to answer. 
But the theory of forms at hand does address this issue. For $a$ to participate in the form of $F$-ness is precisely for $a$ 's $F$-ness to be identical with $F$-ness itself. The $F$-ness of $a$ is part of the visible world, but $F$-ness itself has all the properties of the $F$-ness of $a$, and so is part of the visible world. This does not stop it being part of the intelligible world as well: it is both. This is a contradiction, but such is the nature of the beast. The form crosses the boundary between the two worlds in a contradictory fashion. ${ }^{31}$

Applying this to knowledge: when $a$ knows $f$, then $a$ participates in the form $\pi x(x$ knows $f)$. So $a$ 's knowledge of $f$ is identical with $\pi x(x$ knows $f)$. $a$ 's knowledge of $f$ is part of this world, so $\pi x$ ( $x$ knows $f$ ) has the property of being part in this world, even though it is not. Our theory of forms meets Parmenides' challenge about knowledge.

\section{The Transition between the First and Second Parts of the Dialogue (135c-137c)}

We have now seen how the theory of forms I described addresses and resolves all three of Parmenides' objections. We must now turn to the much harder issue of what on earth is happening in the second half of the dialogue. We morph into the second part of the dialogue with a transition passage.

In the light of Parmenides' arguments, one might expect him, at this point, to reject the theory of forms; but, in the turning point of the dialogue, he says, in effect, that one cannot do this (135b-135c):

"[I]f someone, having an eye on all the difficulties we have just brought up and others of the same sort, won't allow that there are forms for things and won't mark off a form for each one, he won't have anywhere to turn his thought, since he doesn't allow that for each thing there is a character that is always the same. In this way he will destroy the power of dialectic entirely."

\footnotetext{
${ }^{31}$ Note that if $F$-ness is both in and not in this world, we cannot infer that the $F$-ness of $a$ is not in this world. It is simply in this world, and this suffices to make the biconditional of identity true, as we saw in Section 2.
} 
It is not entirely clear what Parmenides takes the problem of giving up the theory of forms to be. ${ }^{32}$ But presumably this is just Plato saying that he is not going to give up the theory. The question must then be how one is to answer Parmenides' objections. Parmenides himself makes a suggestion. To answer the objections one needs a 'proper training' (135d): 'you must not only hypothesize, if each thing is, and examine the consequences of that hypothesis; you must also hypothesize, if that same thing is not' (135e-136a). He explains (136a-136c):

"If you like," said Parmenides, "take as an example this hypothesis that Zeno entertained: if many are, what must the consequences be for the many themselves in relation to themselves and in relation to the one, and for the one itself in relation to itself and in relation to the many? And, in turn, on the hypothesis, if many are not, you must again examine what the consequences will be both for the one and for the many themselves in relation to themselves and in relation to each other. And again, in turn, if you hypothesize if likeness is or is not, you must examine what the consequences will be of each hypothesis, both for the things hypothesized themselves and for the others, both in relation to themselves and in relation to each other. And the same method applies to unlike, to motion, to rest, to generation, to destruction, and to being itself and not-being. And, in a word, concerning whatever you might hypothesize as being or as not being or as having any other property, you must examine the consequences for the things you hypothesize in relation to itself and in relation to each of the others, whichever you select, and in relation to several of them and to all of them in the same way; and, in turn, you must examine the others, both in relation to themselves and in relation to whatever other thing you select on each occasion, whether what you hypothesize you hypothesize as being or as not being. All this you must do if, after completing your training, you are to achieve a full view of the truth."

\footnotetext{
32 'Dialectic' is a translation of 'dialegesthai' which could be translated equally as 'discourse' or 'conversation' (Gill and Ryan (1996), p. 138).
} 
Socrates, not unreasonably, asks for an example. After some hesitation, because of how demanding the task is, Parmenides agrees (137b):

"Well then, at what point shall we start? What shall we hypothesize first? I know: since we have in fact decided to play this strenuous game, is it all right with you if I begin with my own hypothesis? Shall I hypothesize about the one itself and consider what the consequences must be, if it is one or it is not one?"33

It is agreed, and the deductions begin, with Aristotle as respondent (not the Aristotle, another; if, as is said early in the dialogue, Zeno is about 40, the Aristotle would not be born for about another 65 years).

The deduction has four parts. (There is also a somewhat anomolous intrusion: an appendix to the first part. I ignore this until later.) Each part is a pair of arguments, starting with the same assumption, but ending in contradictory conclusions. (Shades of Kant's Antinomies in the first Critique!) The first two parts are subject to the assumption that the one is. The second two are subject to the assumption that it is not. The first and third are about the one. The second and fourth are about the others. Let us write $u$ (unum) for the one, and a (alia) for the others, then the deductions have the following form:

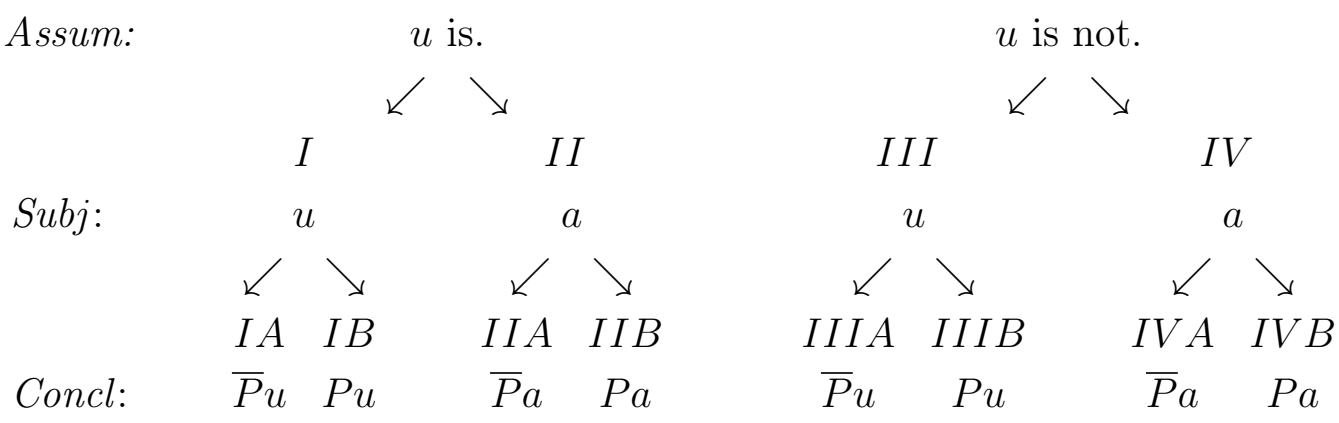

The $P$ s are various. Each $P x$ is to the effect that $x$ has some property, and, generally speaking, is twinned with its negation in a corresponding conclusion of the pair. It should be noted though, that the $P$ s themselves

\footnotetext{
${ }^{33}$ In the context, what one would expect for the last clause is 'if one is, or one is not'. Gill (1996), p. 67, notes that the text can be read this way if it is emended as endorsed by a number of scholars, such as Cornford in Hamilton and Cairns (1961).
} 
are often contradictory (or, at least, contrary) properties, of the form $Q x \wedge$ $\bar{Q} x$. Thus, for example, $I B$ concludes that the one is both at rest and in motion; whilst $I A$ concludes that it is neither at rest nor in motion.

The most obvious issue to be faced at this point is what, exactly, the one is; and, correlatively, what the others are. First, the one. Parmenides calls this 'his own hypothesis', and so we might expect it to be the what is of his poem, whose properties Zeno defended in his book. But in the context, this is implausible. We are in the middle of an argument about the forms; bringing in Parmenides' one at this point would be changing the subject. More plausibly, this is just a literary device on Plato's part, and the one, whatever it is, is a form. Which one? One might suppose that it is any form, but it is more plausible here to suppose that it is one particular form: the form of unity. This makes more sense of the deductions, if only because the first claim in $I A$ is that the one is one. If the one is the form of unity, this holds because of Self-Predication. But the step is not to be taken for granted in the case of other forms. To claim that the many is one, for example, is problematic precisely because of Self-Predication. (Of course, Parmenides has said that we have to undertake the same sort of process with all the things one hypothesizes: the one, the many, likeness, unlikeness, motion, rest, generation, destruction, being, non-being. So there is reason to suppose that Plato is taking the form of unity to be a typical example in some sense.)

If the one is the form of unity, what are the others? There are several possibilities. One is the opposite form, plurality. After all, in Parmenides' first example, the object in question is the many, and this is contrasted with the one. But this seems to be ruled out by the fact that when explaining the general case, Plato uses the plural: others. Another possible answer is that the others are all the instances of the form of unity, all single things. But this cannot be right, just because in Plato's first example the other is a single form, and not those things that instantiate plurality. The most plausible candidates for the others would seem to be other forms. Which ones? One of them, several of them, all of them. You can pursue the method with any of these things it would seem (136b-136c: 'you must examine the consequences for the things you hypothesize in relation to itself and in relation to each of the others, whichever you select, and in relation to several of them and to all 
of them in the same way'). In the case of the deductions given, Plato seems to have no specific others in mind; so the most natural assumption is that the others are all the other forms.

\section{Interlude: Approaches to Part 2}

This brings us to part two itself. How to interpret the second part of the Parmenides is, it seems to me, the key point concerning the interpretation of the text. Before I turn to my commentary on part two, let me digress briefly to note how some more notable commentators have interpreted it. None of them has taken the possibility of contradictory forms seriously. What follows is not intended to be a systematic discussion of the literature. It is just meant to give a feel for the size of the problem at hand.

The traditional Neo-Platonist interpretation of the deductions was to take the first three deductions, $1 \mathrm{~A}, 1 \mathrm{~B}$, and $2 \mathrm{~A}$, as being about different things. They took the subjects of the first three deductions to be the three Hypostases: the One, the Intellect, and the Soul. ${ }^{34}$ The most obvious failing of this approach is that it completely ignores the other five deductions! But there are other problems. Most notably, the text clearly states that deductions $1 \mathrm{~A}$ and $1 \mathrm{~B}$ are about the same thing. Worse, the conclusions of deduction $1 \mathrm{~B}$ are themselves contradictory. So this is no way of obtaining consistency. Finally, and crucially, it is not at all clear how this strategy is meant to address the question of how to solve the problems of part one.

Allen ${ }^{35}$ says that the function of the deductions is simply to induce puzzlement. This seems most implausible. Why would Plato foist on the reader page after page of apparent argument-salad just to induce perplexity? - We were already perplexed by the problems about the forms in the first part of the dialogue anyway! No, we are meant to learn something from the pagesand something, presumably, which tells us how to address the issues raised in the first part.

Some commentators, for example Pemberton (1984), have taken Plato at his apparent word, and endorsed the thought that the second part of the

\footnotetext{
${ }^{34}$ See Dodds (1928).

${ }^{35}$ Allen (1983), pp. vii-viii.
} 
dialogue is indeed a training in dialectics, in preparation for solving these problems. It is most unclear just how following through a bunch of deductions could prepare one to solve the problems. If a training in dialectics were a training in how to analyse and critique arguments, this could be a good preparation; but that is not what we have here. ${ }^{36}$ In the second part of the Parmenides there are not just the arguments, of course. Maybe learning the eight-fold method is supposed to be an essential part of the training. Beyond the rather lame advice 'you should look at both sides of the issue', it is difficult to see how this would really help, though. It is hard to hear Plato's words about a training in dialectics as anything but a literary device on his part. ${ }^{37}$

A much more plausible interpretation of part two is to the effect that the deductions are, in effect, a reductio ad absurdum of some of their premises, and that rejecting these premises will resolve the problems of the first part. This is the response of, for example, Gill (1996), and Rickless (1998). ${ }^{38}$ The problem here is to see which assumptions are to be rejected, and how rejecting them is to solve the problems of part one. Gill ${ }^{39}$ suggest that it is the assumption that the one cannot be many which is to be rejected. We have to suppose that the one can be both one and many - in some presumably consistent way. How to do this, and how, exactly, this will solve the problems of part one, Gill leaves as a challenge for the reader! Rickless suggests more extensive rejections than Gill. He would give up not only what Gill would, but also two further claims: (i) that the form of $F$-ness is unique, and (ii) that if something is $F$ it cannot make anything have a property contrary to $F$. What is worth having of the theory of forms if one rejects (i) is a moot point. But a challenge for Rickless, as it is for Gill, is to explain consistently how an object can have contrary properties. And even then, as he points out, his approach leaves unanswered the question of how to address Parmenides'

\footnotetext{
${ }^{36}$ Cornford (1939), pp. $244-5$, tries to turn it into one, but not in a very helpful way: 'It is a challenge for the student to discover for himself the ambiguities of the Hypotheses and any fallacies there may be in the form of the deductions'.

${ }^{37}$ Maybe what we need a training in, is rejecting the PNC!

${ }^{38}$ Miller (1986) runs a similar line.

${ }^{39}$ Gill (1996), pp. 104-109.
} 
third attack: it is a 'challenge for future work'! ${ }^{40}$

Ryle (1939) urges us to take the deductions in the second part of the Parmenides to show that the assumptions from which they start are not just false but "category mistakes". The trouble with this, is that if we take them to be so, then pretty much the whole theory of forms turns out to be in the same boat. This is less of a defence of the theory of forms then a trashing of it. Ryle appears to accept this conclusion without blinking (p. 314), on the ground that Plato was a great philosopher who was entitled to change his mind. So be it. But then why stitch these deductions together with the more mundane objections of the first part, then declare that it was not possible to give up the theory of forms, and that going through the motion of the deductions would help to resolve the problems?

Another plausible interpretation of the second part of the dialogue is the tried and tested method of distinguo: when in trouble, draw a distinction. The deductions force us to diagnose some ambiguities; this resolves the contradictory conclusions, and the disambiguations also solve the problems of part one. The most notable advocate of the approach is Meinwald (1991). ${ }^{41}$ The idea here is to distinguish between having a property 'for itself' (or pros heauto) and having it 'for another' (or pros ta alla). For each pair in the $A$ and $B$ deductions, one is true in one sense, the other in the other. Some of the arguments here turn on nice points of Greek grammar, but the crucial question is how, exactly, drawing the distinction resolves the problems of part one. Diagnosing an ambiguity does not, generally speaking, make matters better: it makes them worse. For the original arguments now fragment into multiples: one for each possible disambiguation. One must explain why every uniformly disambiguated argument fails to deliver a contradiction. And it would appear that there are versions of at least Parmenides' second attack that go through after disambiguation. ${ }^{42}$ Worse, drawing the distinction and applying it in the way suggested does not resolve all contradictions. A number of the conclusions of arguments $I B$ and $I I A$, for example, even if these are "for itself" or "for another" are themselves contradictory. ${ }^{43}$

\footnotetext{
${ }^{40}$ The last sentence of Rickless (2007).

${ }^{41}$ Scolnicov (2003) has a similar approach.

${ }^{42}$ See Frances (1996).

${ }^{43}$ If one tries to resolve these contradictions by applying the pros heuto/pros ta alla
} 
And when all is said and done, if the lesson of the second part of the Parmenides is that we should reject some premise, or diagnose some ambiguity in the arguments of the first part of the dialogue, it is difficult to see why we need the lengthy and extended deductions that Plato provides. Parmenides' attacks in the first part of the dialogue already provide sufficient ground for making such a move. We do not need more especially the more of the extraordinary kind we find in the second part of the dialogue. If Plato had had such a move in mind, he could simply have had Socrates point it out in the first half of the dialogue. So this is not what Plato intends us to take away from part two.

What I think he intends us to take away is exactly what the dialogue says: the possibility that the forms are contradictory. Let us now turn to this.

\section{Deduction IA (137c-142a)}

Deduction I is by far the longest textually. The first of its parts, $I A$, starts with an instance of Self-Predication, the one is one, and then concludes that the one can neither have parts nor be a whole, as follows (137c-137d):

"If it is one, the one would not be many, would it?"- "No, how could it?"- "Then there cannot be a part of it nor can it be a whole." - "Why?" - "A part is surely a part of a whole."- "Yes.""But what is the whole? Wouldn't that from which no part is missing be a whole?"- "Certainly."-"In both cases, then, the one would be composed of parts, both if it is a whole and if it has parts."- "Necessarily." - "So in both cases the one would be many rather than one." - "True." - "Yet is must be not many but one.""It must."- "Therefore if the one is to be one, it will neither be a whole nor have parts."- "No, it won't."

\footnotetext{
distinction as well, then the contradictions between the conclusions of the $A$ and the $B$ deductions are not resolved. Thus, take conclusion 13 of deduction $I B$. This says that the one is both equal and unequal to itself. If one disambiguates this, then one of these conjuncts will contradict conclusion 10 of argument $I A$, whichever disambiguation of that one takes.
} 
There then follow about five Stephanus pages of tightly reasoned argument. There is no point in hammering through the details of this deduction - or any of the others - here. The steps are many, and there are many places at which one might balk. The point at issue is not whether the arguments are, in fact, cogent, but whether Plato takes them to be plausible. There is no indication that he does not-Aristotle never balks seriously. ${ }^{44}$

The various conclusions reached are all to the effect that the one does not have various properties, which are listed in the following table. ${ }^{45}$ I put the conclusions of $I B$ on the same table for comparison. ${ }^{46}$ The numbers in the columns represent the order in which the conclusions are reached. It is worth noting that the conclusions of $I A$ are, for the most part, those about what is, which the historical Parmenides argued for in his poem. ${ }^{47}$ Naturally, this can hardly be a coincidence.

\footnotetext{
${ }^{44}$ One might argue about the exact logical form of each argument, but it is clear that many of the arguments are by contraposition. This is valid in most paraconsistent logics: $A \rightarrow B \vdash \neg B \rightarrow \neg A$. Even forms of reductio are valid in paraconsistent logics with Excluded Middle and De Morgan. For then $A \rightarrow(B \wedge \neg B) \vdash \neg(B \wedge \neg B) \rightarrow \neg A \vdash$ $(\neg B \vee B) \rightarrow \neg A$, and Excluded Middle does the rest.

${ }^{45}$ Of course, how one pulls out the vertebral conclusions is, to a certain extent, a matter of judgment. The tables that follow are taken with minor amendments from Gill (1996), pp. 117-123. The numbering is hers.

${ }^{46}$ Except 2, which is not about the one. I will comment on this later.

${ }^{47}$ See, e.g, Barnes (1987), pp. 134-5.
} 


\begin{tabular}{|c|c|c|c|}
\hline & Deduction IA & & Deduction IB \\
\hline 1. & Is not many. & & \\
\hline 2. & $\begin{array}{l}\text { Is not a whole and } \\
\text { does not have parts. }\end{array}$ & 3. & $\begin{array}{l}\text { Is a whole and } \\
\text { has parts. }\end{array}$ \\
\hline \multirow[t]{2}{*}{3.} & $\begin{array}{l}\text { Does not have a beginning, } \\
\text { middle or end. }\end{array}$ & 6. & $\begin{array}{l}\text { Has a beginning, } \\
\text { middle, and end. }\end{array}$ \\
\hline & & 4. & Is unlimited in multitude. \\
\hline 4. & Is unlimited. & 5. & Is limited. \\
\hline 5. & Is without shape. & 7. & Has a shape. \\
\hline 6. & Is not in itself or another. & 8. & Is in itself and others. \\
\hline 7. & Is not in motion or at rest. & 9. & Is in motion and at rest. \\
\hline 8. & $\begin{array}{l}\text { Is not the same as or different } \\
\text { from another or itself. }\end{array}$ & 10. & $\begin{array}{l}\text { Is the same as and different } \\
\text { from itself and others. }\end{array}$ \\
\hline \multirow[t]{2}{*}{9.} & $\begin{array}{l}\text { Is not like or unlike } \\
\text { another or itself. }\end{array}$ & 11. & $\begin{array}{l}\text { Is like and unlike } \\
\text { the others and itself. }\end{array}$ \\
\hline & & 12. & $\begin{array}{l}\text { Touches and does not touch } \\
\text { the others or itself. }\end{array}$ \\
\hline 10. & $\begin{array}{l}\text { Is not equal to or unequal } \\
\text { to itself or another. }\end{array}$ & 13. & $\begin{array}{l}\text { Is equal and unequal } \\
\text { to the other and itself. }\end{array}$ \\
\hline 11. & $\begin{array}{l}\text { Is not younger than, } \\
\text { older than, or the same } \\
\text { age as itself or another. }\end{array}$ & 15 . & $\begin{array}{l}\text { Is and comes to be older and } \\
\text { younger than itself and the others } \\
\text { and neither comes to be older or } \\
\text { younger than itself and the others. }\end{array}$ \\
\hline 12. & Is not in time. & $\begin{array}{l}14 . \\
16 .\end{array}$ & $\begin{array}{l}\text { Is in time. } \\
\text { Partakes of past, present, future. }\end{array}$ \\
\hline 13. & Is not. & 1. & Partakes of being. \\
\hline 14. & Is not one. & & \\
\hline 15. & $\begin{array}{l}\text { Is not named or spoken of, } \\
\text { or the object of opinion, } \\
\text { knowledge or perception. }\end{array}$ & 17. & $\begin{array}{l}\text { Is named and spoken of, } \\
\text { and is the object of opinion, } \\
\text { knowledge, and perception. }\end{array}$ \\
\hline
\end{tabular}

In fact, there is a single argument that underlies all the conclusions of $I A$. It is invoked explicitly at conclusion 9 (139e-140a, my italics): 
"Furthermore, it will be neither like nor unlike anything, either itself or another."- "Why?"- "Because whatever has a property the same is surely like."- "Yes."- "But it was shown that the same is separate in nature from the one."-"Yes it was."- "But if the one has any property apart from being one, it would be more than one; and that is impossible."- "Yes."-"Therefore the one can in no way have a property the same as another or itself."- "Apparently not." - "So it cannot be like another or itself either." - "It seems not."

If the one had any properties other than being the one, it would be a manyit would have parts: its $P$-ness, its $Q$-ness, etc.- which is what it is not, as was said right at the beginning.

It should be noted that conclusion 13 is anomalous in a certain sense. All the conclusions up to this point are, at least prima facie, consistent; but conclusion 13 denies the assumption of the whole deduction. In a similar way, conclusion 14 denies the initial application of Self-Predication in the argument. (Conclusion 15 is not inconsistent in the same way, though it is self-referentially inconsistent.) I will return to this later. For the moment, just note that the conclusions of $I A$ are sufficient, in themselves, to establish that the one has certain contradictory properties. But you ain't seen nothin' yet.

\section{Deduction IB (142a-155e)}

$I A$ concludes as follows (142c):

"Is it possible that these things are so for the one?"- "I certainly don't think so."

So one might expect Parmenides or Aristotle to go back on something. (And some commentators do take this as a hint that we need to go back on something.) But this is not what we find. What we find is this (142b-142c):

"Do you want to return to the hypothesis from the beginning, in the hope that another kind of result may come to light as we go 
back over it?"- -"I do indeed."- "If one is, we are saying, aren't we, that we must agree on the consequences for it, whatever they happen to be?"- "Yes."- "Consider from the beginning: if one is, can it be, but not partake of being?"- "It cannot."-"So there would also be the being of the one, and that is not the same thing as the one. For if it were, it couldn't be the being of the one, nor could the one partake of it. On the contrary, saying that one is would be like saying that one is one. But this time that is not the hypothesis, namely, what the consequences must be, if one is one, but if one is. ${ }^{48}$ Isn't that so?"- "Of course."- "Is this because "is' signifies something other than 'one'?"- "Necessarily." - "So whenever someone, being brief, says 'one is', would this simply mean that the one partakes of being?"- "Certainly".

No taking back. We get more: all of $I B$. This deduction amounts to 13 Stephanus pages - more than all the other deductions put together; but its germ is already in the passage just quoted. The one is, so it is one and has being. Being is different from oneness. (Gill lists this as the first conclusion in $I B$, but it is not about the one, and I think it better to take it to be an intermediate step.) So the one has at least two distinct properties. It therefore has parts, and so off we go. What we find, generally speaking, in $I B$ is a mate which is the negation of each conclusion in $I A$. The one, then, is established to have a whole bunch of contradictory properties. The order in which these properties are established is not exactly the same as in $I A$, but it is obviously reasonable to allow Plato some slack here.

There are a few exceptions to this general picture. 14 of $I A$ has no mate, though it contradicts the initial application of Self-Predication, as we have already observed. Neither does 1 , that the one is not a many. But Plato fills that gap en passant in $I B$ - twice in fact. The one has parts, and 'for this reason the one that is was shown to be many' (143a). And again: the one has many parts, and each of these is one, so 'not only is it that the one being is many, but also that the one itself, completely distributed by being, must

\footnotetext{
${ }^{48}$ Cornford translates this, a bit more intelligibly, as "But in fact, the supposition whose consequences we are to consider is not 'if one [is] one', but 'if one is.'" (Hamilton and Cairns (1961).)
} 
be many' (144e). So all the conclusions of $I A$ are contradicted somewhere.

The aberrations are more anomalous in $I B$. 16 of $I B$ appears to be little more than a stylistic variation of 14 , perhaps repeated for exegetical reasons. At any rate, it mates explicitly with $141 \mathrm{~d}-142 \mathrm{e}$ of $I A$, where it is spelled out that the one is not past, present, or future.

For 4 of $I B$, Plato gives two recursive-style arguments to the effect that the one has not just two parts but an infinite number, and so is unlimited (142d-144e). This conclusion has no explicit mate in IA. But, oddly, it itself already occurs at 4 in $I A$ - though the argument used to establish it there is quite different - and so contradicts the mate of $4: 5$, in $I B$.

12 of $I B$ appears to correspond to nothing in $I A$. Its conclusion is to the effect that the one both touches and does not touch itself and the others. However, this conclusion is self-contradictory, and its negative parts could have appeared under $I A$, because of the general argument that the one cannot have any positive properties other than being one. 15 of $I B$ is a mate of 11 in $I A$, but also goes on to repeat its negative claims.

So, anomalies notwithstanding, each claim of $I A$ and $I B$ is actually contradicted somewhere in the ledger. This is, in fact, exactly what one should expect on the model of the forms at hand. Oneness will have each property that the oneness of each one thing has. Given the plausible assumption that the $F$-ness of $x$ is located where $x$ is, this is going to ensure many contradictory properties. Some one things are in motion (and so not at rest), so oneness is in motion (and not at rest). Some one things are at rest (and so not in motion), so oneness will be at rest (and not in motion). Everything is touched by some one thing, so everything is touched by oneness. But everything is not touched by something, so everything will not be touched by oneness. The oneness of anything is identical to itself. So oneness is identical with itself. The oneness of Socrates is distinct from the oneness of Plato. So oneness is distinct from the oneness of Plato; and so oneness is distinct from itself. And so on. One may, perhaps, have to stretch things sometimes to show that oneness has all the contradictory pairs on the list. (I will return to this matter in due course.) But the general point is clear: given the theory of forms at hand, one should expect the form of unity to have exactly the sort of contradictory properties that Deduction $I$ establishes. 
Perhaps more importantly, what drives the deductions $I A$ and $I B$ is one fundamental contradiction. For $I A$, the one is one and so not many. For $I B$, the one is many - and so not one. This is what the gluon model of the forms delivers. As before, let $u$ be unity (the one), and let $u_{S}, u_{P}, u_{A} \ldots$ be the unity of Socrates, the unity of Plato, the unity of Aristotle, etc. Then $u=u$ : one is one; but $u_{S} \neq u_{P}$, so $u_{S} \neq u$, and similarly, $u_{P} \neq u$, etc.; so the one is not many. But by the properties of gluons, $u=u_{S}, u=u_{P}, \ldots$, and since these are all distinct, $u$ is a many; finally, since $u_{P} \neq u_{S}, u \neq u$ : the one is not one. In Plato's actual argument, the multitude are not the concrete instances of the form; the various properties of the form are taken to deliver its multitude: unity's oneness, unity's being, etc. But we can think of Socrates' unity, Plato's unity, etc., equally well, as unity's Platoness, unity's Socratesness, etc.; so we are not so far away.

\section{Deduction II (157b-160b)}

There is, as I have already observed, an anomalous appendix to Deduction $I$. Let us return to this later, and pass on to Deduction $I I$. Deduction $I I$ retains the assumption that the one is, and considers the properties of the others - the other forms (159b-159c):

"Must we not examine what would be proper for the others to undergo, if one is?"- "We must."- "Are we to say, then, what properties things other than the one must have, if one is?"- "Let's do." - "Well then, since they are other than the one, the things are not the one. For if they were, they would not be other than the one."- "That's right."

The nerve of the deduction concerns wholeness and parthood. Even though the others are not one, they partake of the one in some sense (157c-158a):

"And yet the others are not absolutely deprived of the one, but somehow partake of it."- - In what way?"- - In that things other than the one are surely other because they have parts; for if they didn't have parts, they would be altogether one."- "That's 
right."- "And parts, we say, are parts of that which is a whole?""Yes, we do."- "Yet the whole of which the parts are to be parts must be one thing composed of many, because each of the parts must be part, not of many, but of a whole." ... "So the part would not be part of many things or all, but of some one character and of some one thing, which we call a 'whole', since it has come to be one complete thing composed of all. This is what the part would be part of."- "Absolutely." - "So if the others have parts, they would also partake of some one whole."- - "Certainly."- - "So things other than the one must be one complete whole with parts."

The whole is one thing, and so the parts which comprise it partake of the one in some sense. And, Parmenides goes on to note, each part is also severally one. Having established these things, the deduction proceeds. It is much shorter than the two previous ones, but that is partly because Plato truncates it abruptly (159a-159b):

"And indeed we will have no further trouble in finding that things other than the one are both the same and different from each other, both in motion and in rest, and have all the opposite properties, since in fact they were shown to have those we mentioned.""You're right."

How one is to do this, is - it must be said - not immediately obvious. The following table lists the conclusions about the others in $I I A$ - and in $I I B$ for comparison. 


\begin{tabular}{|c|l||c|l|}
\hline & Deduction IIA & & Deduction IIB \\
\hline \hline & & 1. & Are separate from the one. \\
\hline 1. & Are not the one. & & \\
\hline 2. & Somehow partake of the one. & 2. & Are in no way one. \\
\hline 3. & Are many. & 3. & Are not many. \\
\hline 4. & $\begin{array}{l}\text { Are unlimited and } \\
\text { partake of a limit. }\end{array}$ & & \\
\hline 5. & $\begin{array}{l}\text { Are like and unlike } \\
\text { themselves and others. }\end{array}$ & 4. & $\begin{array}{l}\text { Are not like or } \\
\text { unlike the one. }\end{array}$ \\
\hline 6. & Have all the other properties. & 5. & Have no other properties. \\
\hline
\end{tabular}

Deduction $I I B$ now goes back to the start again (159b):

"Well then, suppose we now concede those results as evident and examine again, if one is: Are things other than the one also not so, or only so?"- "Of course."- "Let's say from the beginning, what properties things other than the one have, if one is."- "Yes, let's do."

The nerve of this deduction is again the relationship between parts and wholes $(159 \mathrm{c}-\mathrm{e})$ :

"Furthermore, we say that what is really one doesn't have parts.""Obviously not." - "So the one could not be in the others as a whole, nor could parts of it be in them, if it is separate from the others and doesn't have parts."- "Obviously not." - "So the others could in no way partake of the one, if they partake neither by getting some part of it nor by getting it as a whole. "It seems not."- "In no way, then, are the others one, nor do they have any oneness in them."-"Yes, you're quite right."

"So the others aren't many either; for each of them would be one part of a whole, if they were many ... Therefore, the others are not themselves two or three, nor are two or three in them, if they are entirely deprived of the one."- "Just so." 
Having established that the others are neither a one nor a many, the rest of the deduction is relatively terse, concluding, this time, with a general argument for most of the properties at issue (160a-160b):

"So they are neither the same nor different, neither in motion nor at rest, neither coming to be nor ceasing to be, neither greater nor less nor equal. Nor do they have any such properties. For if the others submit to having any such property, they will partake of one and two and three and odd and even, of which it was shown that they could not partake, since they are in every way deprived of the one."-"Very true."

If the others have any of the properties in question, they can be numbered, which, it has been established, they cannot be.

The final conclusion of the deduction appears somewhat anomolous, since it summarises the result of just Deduction $I$ (160b): ${ }^{49}$

"Thus, if one is, the one is all things, and not even one, both in relation to itself and, likewise, in relation to the others." "Exactly."

Be that as it may, as consulting the previous table shows, deduction $I I$ has established that the others have a bunch of properties - many of them themselves contradictory - and do not have them. The first conclusions in each of $I I A$ and $I I B$, are, interestingly enough, much the same, and set up the subsequent trains of deduction. After that, the conclusions pair off, one for one, with the exception of 4 of $I I A$, which is appealed to in establishing 5 , and may therefore be taken to be merely an intermediate conclusion.

So now we have inferred that all the forms, not just the form of unity, have contradictory properties - as they should have on the gluon theory of forms at issue here. For just as the one has all the properties of the oneness of Socrates, the oneness of Plato, etc., so for any other form $F$, if $x, y, \ldots$

\footnotetext{
${ }^{49}$ Gill (1996), p. 391, notes that with an emendation of the text, as endorsed by some commentators (e.g., Meinwald (1991), pp. 142-4), this can be rectified, so that the translation is: "Thus, if one is, the one is all things and not even one, both in relation to itself and in relation to others, and likewise for the others".
} 
are the things that are $F, F$-ness has the properties of the $F$-ness of $x$, the $F$-ness of $y$, etc.

Since $I I A$ and $I I B$ turn on the properties of parts and wholes, and since the theory of forms at issue here piggy-backs on an account of these, it is worth looking at the treatment of parts and wholes in Deduction II in more detail, before we pass on to the other deductions. The two parts of the deduction together pose a challenge. A whole is composed of parts, but it is more than the plurality of the parts: it forms a unity. As Parmenides says (157c):

"Yet the whole of which the parts are to be parts must be one thing composed of many, because each of the parts must be part, not of many, but of a whole."

Parmenides suggests that it is by participating, in some sense, in unity that the parts come to form a whole. As he put it darkly when discussing conclusion 4 of $I I A$ (158d, my italics):

"Furthermore, whenever each part comes to be one part, the parts then have a limit in relation to each other and to the whole, and the whole has a limit in relation to the parts."-"Quite so.""Accordingly, it follows for things other than the one that from the one and themselves gaining communion with each other, as it seems, something different comes to be in them, which affords a limit; but their own nature, by themselves, affords unlimitedness."

But, according to $I I B$, this cannot be the case. For if each part partook of the form of the one, the whole would not be one, which it is $(159 \mathrm{c}-159 \mathrm{~d})$ :

"Furthermore, we say that what is really one doesn't have parts.""Obviously not."- "So the one could not be in the others as a whole, nor could parts of it be in them, if it is separate from the others and doesn't have parts."- - Obviously not."-"So the others could in no way partake of the one, if they partake neither by getting some part of it nor by getting it as a whole. "It seems 
not."- "In no way, then, are the others one, nor do they have any oneness in them."- "Yes, you're quite right."

What to say of this? According to the present theory, Socrates, for example, is one object with parts. To be one, he has a gluon - we might even take to be his trope of unity. The gluon, anyway, comes to be, and so becomes a part, when the other parts become one - when, one might say, repeating what Parmenides says in the italicised phrase, they commune with the one. But the whole is one thing, and each part is also one thing, contrary to the claim made in the II B argument. Plato simply assumes that something with parts cannot be a true unity. Gluon theory explains how it is.

It may fairly be asked why we do not take it to be oneness itself which binds together the parts of any one object. The reply is that there would not then be sufficient discrimination. Suppose this were, in fact, the case. The parts of Socrates would form a one, and so would participate in oneness. The parts of Plato would form a one, and so would participate in oneness. So the parts of Socrates and Plato together would participate in oneness, and so be one. Indeed, all one things would be one. Perhaps they are; but we would now be bereft of an explanation of what makes Socrates, Plato, etc., distinct ones. Whatever it is that explains why the parts of Socrates are one must be relational in some sense. They must relate to the parts of Socrates, but not the parts of Plato. This raises other, regress, worries that surface in later deductions. So let us move on to Deduction III.

\section{Deduction III (160b-164b)}

At this stage, we have established that oneness, and all the other forms, have contradictory properties. The deductions do not finish here, however. Parmenides reminds us that we now need to look at the other side of the picture and consider what is the case if the one is not (160b-160d). The topic in Deduction $I I I$ is back to the one (160d):

"Then we must start from the beginning as follows [sic] what must

be the case, if one is not. First, this must be so for it, that there 
is knowledge of it; otherwise we don't even know what is meant when someone says, 'if one is not'."- "True."...

The conclusions of III A concerning the one are given in the following table, with $I I I B$ for comparison. ${ }^{50}$

\begin{tabular}{|c|c|c|c|}
\hline & Deduction IIIA & & Deduction IIIB \\
\hline & & 10. & Is in no state at all. \\
\hline \multirow[t]{2}{*}{1.} & Is knowable. & 9. & $\begin{array}{l}\text { Knowledge, etc., } \\
\text { are not applicable to it. }\end{array}$ \\
\hline & & 8. & $\begin{array}{l}\text { Past, present, and future } \\
\text { are not applicable. }\end{array}$ \\
\hline 2. & Is different from the others. & $7 .^{\prime}$ & $\begin{array}{l}\text { It is neither like nor different } \\
\text { from itself or others. }\end{array}$ \\
\hline 3. & $\begin{array}{l}\text { Partakes of that, } \\
\text { something, this, etc. }\end{array}$ & 7. & $\begin{array}{l}\text { This, that, something, etc., } \\
\text { are not applicable to it. }\end{array}$ \\
\hline 4. & $\begin{array}{l}\text { Is unlike the others, } \\
\text { and like itself. }\end{array}$ & $6 a$. & $\begin{array}{l}\text { The others are neither like it } \\
\text { nor unlike it. }\end{array}$ \\
\hline 5. & Is not equal to the others. & $6 b$. & $\begin{array}{l}\text { The others are neither the same } \\
\text { as nor different from it. }\end{array}$ \\
\hline \multirow[t]{2}{*}{$5 .^{\prime}$} & $\begin{array}{l}\text { Has a share of equality, } \\
\text { largeness and smallness. }\end{array}$ & $5 .^{\prime}$ & $\begin{array}{l}\text { Largeness, smallness and } \\
\text { equality do not belong to it. }\end{array}$ \\
\hline & & 5. & Nothing that is belongs to it. \\
\hline 6. & Somehow partakes of being. & 1. & In no way partakes of being. \\
\hline 7. & Has being and not being. & & \\
\hline 8. & Is in motion and at rest. & 4. & Is neither in motion nor at rest. \\
\hline 9. & $\begin{array}{l}\text { Is both altered and } \\
\text { not altered. }\end{array}$ & 3. & Is not altered. \\
\hline 10. & $\begin{array}{l}\text { Comes and ceases to be, } \\
\text { and neither comes } \\
\text { nor ceases to be. }\end{array}$ & 2. & Neither comes nor ceases to be. \\
\hline
\end{tabular}

\footnotetext{
${ }^{50}$ The numbering is again Gill's, except that the primes account for my slight restructuring.
} 
The pivots of the deduction in IIIA are two. First, for 3, Parmenides points out that if the one is not, or anything else is true of it, it must be possible to predicate things of it, and so to describe it (160e-161a):

"Furthermore, the one that is not partakes of that and of something, this, to this, these, and so on; for the one could not be mentioned, nor could things be different from the one, nor could anything belong to it or be of it, nor could it be said to be anything, unless it had a share of something and the rest."- "That's right."- "The one can't be, if in fact it is not, but nothing prevents it from partaking of many things. Indeed, it's even necessary, if in fact it's that one and not another that is not. If, however, neither the one nor that is not to be, but the account is about something else, we shouldn't even utter a sound. But if that one and not another is not to be, it must have a share of that and of many other things."- "Quite certainly."

Parmenides seems on pretty safe ground here.

The other pivot is the very Parmenidean thought that anything one can speak about has being. ${ }^{51}$ As he puts it (161e-162b):

"Furthermore, it must also somehow partake of being."- "How is that?"- "It must be in the state we describe; for if it is not so, we wouldn't speak truly when we say that the one is not. But if we speak truly, it is clear that we say things that are. Isn't that so?"- - "It is indeed so.- -And since we claim to speak truly, we must claim also to speak of things that are."-"Necessarily." ... "Then the one, if it is not, appears also to have being.""Apparently."- "And of course not-being, if in fact it is not.""Doubtless."

Thus, we have conclusion 6 of $I I I A$; and so, as Parmenides points out at the end of that quotation, by our assumption that one is not, the contradictory 7. We need not pause over the deductions of the other conclusions.

\footnotetext{
${ }^{51}$ Which is acceptable if 'being' means 'being something', but not if it means 'exists'. See Priest (2005).
} 
Before we move on to Deduction $I I I B$, it is worth pausing for a moment. In the passage omitted in the last quotation, Parmenides gives an argumentas the historical Parmenides does not - as to why if one speaks of something it must be. ${ }^{52}$ The argument concerns the one, but is quite general, and goes as follows (162a-162b). This has to be read very slowly and carefully!

"Therefore, as it seems, the one is a not-being; for if it is not to be a not-being, but is somehow to give up its being in relation to not-being, it will straight away be a being."- "Absolutely." - "So if it is not to be, it must have being a not-being as a bond in regard to its not-being, just as, in like manner, what is must have notbeing what is not, in order that it, in its turn, may completely be. This is how what is would most of all be and what is not would not be: on the one hand, by what is, if it is completely to be, partaking of being in regard to being a being and of not-being in regard to being a not-being; and, on the other hand, by what is not, if in its turn what is not is completely not to be, partaking of not-being in relation to not-being a not-being and of being in regard to being a not-being." ${ }^{3}$ _ "Very true." - "Accordingly, since in fact what is has a share of not-being, and what is not has a share of being, so, too, the one, since it is not, must have a share of being in regard to its not-being."

In general terms, the crux of the argument is this. For $a$ to be $F$, there must be a bond between $a$ and $F$-ness. This is being. Hence, $a$ partakes of being. Symmetrically, if $a$ is not $F$, then not-being is a bond between $a$ and $F$-ness, so $a$ partakes of non-being. Thus, being and non-being are predication. Consider being. (The issue concerning non-being is the same.) In the notation of Section 3, to say that $P a$ is to say that $a \rightarrow \pi x P x$, where

\footnotetext{
${ }^{52}$ For seeing the significance of this, I am indebted to Gill (1996), p. $96 \mathrm{ff}$.

${ }^{53}$ I think that this sentence should be: "on the one hand, by what is, if it is completely to be, partaking of being in regard to being a being and of not-being in regard to not-being a not-being; and, on the other hand, by what is not, if in its turn what is not is completely not to be, partaking of not-being in relation to not-being a being and of being in regard to being a not-being."- which is effectively the way Cornford translates it in Hamilton and Cairns (1961).
} 
$\rightarrow$ is participation/being. But if a bond is required in the first place, a bond is equally required in this new case. So we must have $a \rightarrow \pi y(y \rightarrow \pi x P x)$. And so on. We have a Bradley-style regress, which is vicious, since no bond ever gets to do any bonding. This is a problem for Plato. Since part of the claim of this paper is that the theory of forms on offer provides a solution to Plato's problems concerning predication, it is worth noting that it solves this one too. According to the theory, to say that $a \rightarrow \pi x P x$ is to say that $a$ has a trope, $p$, such that $p=\pi x P x$. If, instead of ' $p=\pi x P x^{\prime}$ ' we had ' $p \rightarrow \pi x P x$ ', we would obviously have a regress; but we do not. Since $p$ is identical with $\pi x P x$, no further bonding-agent is required to hold them together.

Now to $I I I B$. The deductions in $I I I B$ start thus (163b-163d):

"Let's go back again to the beginning to see whether things will appear the same to us as they do now, or different."- "Indeed, we must."- "Aren't we saying, if one is not, what the consequences must be for it?"-_Yes."- "When we say 'is not', the words don't signify anything other than the absence of being for whatever we say is not, do they?'-"Nothing other."- -"When we say that something is not, are we saying that in a way it is not, but in a way it is? Or does this 'is not' signify without qualification that what is not is in no way at all and does not in any way partake of being?"- - Absolutely without qualification."- "Therefore what is not could neither be nor partake of being in any other way at all."-"No it couldn't."

And finish thus (164a-164b):

"What about this? Can the others be related to it, if necessarily, nothing belongs to it?"- "They can't."- So the others are neither like nor unlike it, and they are neither the same as nor different from it."- "No, they aren't."- "And again: will of that, to that, something, this, of this, of another, to another, or time past, hereafter, or now, or knowledge, opinion, perception, and account, a name, or anything else that is be applicable to what is not?""It will not."- "Thus one, since it is not, is not in any state at all."- "At any rate, it certainly seems to be in no state at all." 
In fact, the whole deduction turns round the contrapositive of the second pivot of $I I I A$. What is not can have no properties. This is stated at 5 of $I I I B$ (164a): "But in fact, nothing that is belongs to it; for then, by partaking of that, it would partake of being."- "Clearly." And of course, anything one can talk about is. Every other conclusion of IIIB follows.

A striking fact about Deduction III is that Plato chooses to establish the corresponding consequences of its two parts in inverse orders. However, as I have just observed, he could have established 5 first, and then everything else would be a corollary; so he could have ordered the conclusions of $I I I B$ in essentially the same order as those of $I I I A$. Why he chose not to do this, I have no idea.

Another slight oddity of $I I I A$ and $I I I B$ is that some conclusions in one deduction have no mates in the other. The negative half of 7 in IIIA could equally be in the $I I I B$ column. 10 in $I I I B$ is really just a summary of what precedes it. This leaves 5 and 8 of $I I I B$ opposite genuine blanks. It would have been easy enough for Plato to fill them in. If one is not, then non-being belongs to it, and non-being, like all things, is. This gives 5 a mate. And Parmenides has already claimed that if something is, it is in time, and so partakes of past, present, and future (151e-152a). This gives 8 a mate. Why he did not fill in the blanks, again I have no idea.

At any rate, these aberrations aside, by the end of $I I I B$, we have established that if one is not, it has contradictory properties. We now come to the crucial question of why Plato is going through this exercise. The reason, I take it, is as follows: Plato thinks that the one is. Deduction $I$ has established that it has contradictory properties. If I am right, he takes these conclusions seriously. He expects people-perhaps his own prior self, perhaps others (I will return to the question of who Plato takes his opponents to be at the end of this paper) - to object. The function of Deduction III is to show that you are stuck with contradictions even if you suppose that the one is not. So you might as well get used to it! This, of course, was the strategy articulated by Zeno at the very start of the dialogue. 


\section{Deduction IV (164b-165d)}

And so we come to the final deduction, $I V$. It is still supposed that the one is not, but now we establish the properties of the others on this assumption. Parmenides commences Deduction $I V A$ as follows (164b), and starts by establishing that the others are a plurality:

"Let's go on and say what properties the others must have, if one is not."- "Yes, let's do."- "They must surely be other; for if they weren't even other, we wouldn't be talking about the others.""Just so."- "But if the argument is about the others, the others are different. Or don't you apply the names 'other' and 'different' to the same thing?"- - "I do."- -"And surely we say that the different is different from a different thing, and the other is other than another thing?"- "Yes."- "So the others, too, if they are to be other, have something they will be other than?"- "Necessarily.""What would it be then? For they won't be other than the one, if it is indeed not."- "No, they won't."- "So they are other than each other, since that alternative remains for them, or else to be other than nothing."- "That's right."

"So they each are other than each other as multitudes; for they couldn't be so as ones, if one is not. But each mass of them, is unlimited in multitude..."

And concludes (165d-165e):

"Accordingly, if one is not and many are, the many must appear both the same as and different from each other, both in contact and separate from themselves, both moving with every motion and in every way at rest, both coming to be and ceasing to be and neither, and surely everything of that sort, which would now be easy enough for us to go through." - "Very true indeed."

Whether it is very true is a moot point. The arguments are getting terser and terser, and it is not clear how one would fill in all the details. The conclusions of $I V A$ and $I V B$ about the others are listed in the following table. ${ }^{54}$

\footnotetext{
${ }^{54}$ Again, the primes indicate a variation from Gill.
} 


\begin{tabular}{|c|c|c|c|}
\hline & Deduction IVA & & Deduction IVB \\
\hline & & 1. & Are neither one nor many. \\
\hline 1. & Are other than the others. & & \\
\hline 2. & $\begin{array}{l}\text { Are each a mass unlimited } \\
\text { in multitude. }\end{array}$ & & \\
\hline 3. & Appear one, but are not so. & 2. & $\begin{array}{l}\text { Don't appear to be } \\
\text { one or many. }\end{array}$ \\
\hline 4. & $\begin{array}{l}\text { Appear to be numbered, } \\
\text { but are not. }\end{array}$ & & \\
\hline 5. & Appear equal and unequal. & & \\
\hline 6. & Appear limited and unlimited. & & \\
\hline 7. & $\begin{array}{l}\text { Appear to be both like and unlike } \\
\text { themselves and each other. }\end{array}$ & $2^{\prime}(a)$ & Are neither like nor unlike. \\
\hline $7^{\prime}$. & $\begin{array}{l}\text { Appear to be the same and } \\
\text { different, in contact } \\
\text { and separate, etc. }\end{array}$ & $2^{\prime}(b)$ & $\begin{array}{l}\text { Are neither the same nor } \\
\text { different, in contact } \\
\text { or separate, etc. }\end{array}$ \\
\hline 8. & $\begin{array}{l}\text { Appear to have all the } \\
\text { usual opposites. }\end{array}$ & 3. & $\begin{array}{l}\text { Neither are nor appear } \\
\text { to have any of the } \\
\text { usual opposites. }\end{array}$ \\
\hline & & 4. & Nothing is. \\
\hline
\end{tabular}

The most striking thing about the chain of deductions in $I V A$ is the appearance of the notion of appearance. After the first few moves, each conclusion is of one of the forms:

(i) appears to be so, but is not

(ii) appears to be both so and not so

Why does Plato bring in the notion of appearances at this stage? This would certainly seem to be a nod in the direction of the historical Parmenides. The Parmenides' deductions start, effectively, with a recapitulation of the first part of the historical Parmenides' poem; this is about what is. The next part of his poem was about the world of appearances. So it is at least appropriate 
for Plato to finish his deduction with the world of appearances as well. Let us come back to this in a moment.

Deduction $I V B$ begins (165e):

"Let's go back to the beginning once more and say what must be the case, if the one is not, but things other than the one are.""Yes, let's do."-"Well, the others won't be one."-"Obviously not."- - And surely they won't be many either, since oneness would also be present in things that are many. For if none of them is one, they are all nothing — so they couldn't be many." - "True.""If oneness isn't present in the others, the others are neither many nor one."- "No, they aren't."

And concludes (175b-175c):

"So they aren't like or unlike either."-"No, they aren't."- -"And indeed, they are neither the same nor different, neither in contact nor separate, neither anything else that they appeared to be in the argument we went through before. The others neither are nor appear to be any of those things, if one is not."-"True."-"Then if we were to say, to sum up, 'if one is not, nothing is,' wouldn't we be speaking correctly?"-_- Absolutely."

The deduction is by far the shortest, well under one Stephanus page. Parmenidesor Plato - is clearly running out of steam, and the tight correspondence between the $A$ conclusions and the $B$ conclusions has disappeared. For the most part, the main form of the conclusion of the $B$ deduction is:

neither appears to be (so or not so), nor is (so or not so)

The first conjunct contradicts the generic form (ii) of the $A$ conclusions, and the second conjunct grounds the final nihilistic conclusion: nothing is.

We may again ask what Plato is up to here. The answer is essentially as in the case for deductions $I$ and $I I I$. Deduction $I I$ has shown that if the one exists, which of course Plato takes it to do, the other forms have contradictory properties. Deduction $I V$ has shown that even if the one does not exist, the other forms have contradictory properties of the form: appear 
to be so and not so and do not appear to be so or not so. So we may as well accept the contradictory nature of the forms anyway. As Parmenides puts it in the very last statement of the dialogue (166c):

"Let us say ..., as it seems, whether one is or is not, it and the others both are and are not, and both appear and do not appear all things in all ways, both in relation to themselves and in relation to others."-"Very true."

- though this is a bit of an overstatement. No conclusions about how the one appears were drawn. And the "all things in all ways" is presumably all the things and ways of the kind discussed, not literally all things: no attempt was made, for example, to establish that the one is a frog. ${ }^{55}$

There is a stronger point here as well. Assuming that the one is not, we now have not just contradictory conclusions, but the nihilist conclusion that nothing is ( $I V B$, conclusion 4) as well. This seems even more absurd. Some things are, after all, more absurd than some contradictions: that you are a frog is more absurd than that the liar sentence is both true and false. So the final nihilistic conclusion can be seen as making the point that the consequences of the one not being are not just as bad as those of its being; they are worse.

There is an apparent problem with this line of thought, though. In deduction $I A$, Plato himself has argued that if the one exists, then it does not exist-conclusion 13. It would therefore seem that he himself is committed to the consequences of this, and so to this nihilism. What is one to say about this ${ }^{56}$

Perhaps Plato just didn't notice the matter. After all, as we all know, it is easy to miss what is obvious in retrospect. Moreover, there is an obvious thing he could say once he does notice the matter. Deduction $I A$ infers conclusion 13 from conclusion 12: the one is not in time, and so does not exist. He could just reject this conclusion, and truncate $I A$ at this point.

\footnotetext{
${ }^{55}$ It should be remembered that natural-language quantifiers normally have a range determined by the context, as in: 'Everyone has voted'.

${ }^{56} \mathrm{I}$ am not the first person to note this oddity. For discussion and references, see Petersen (1996).
} 
Given his view of forms, he should have done this anyway. Moreover, and notably, the gluon model itself tells us that the non-existence of the one is not to be expected. The one has all the properties of the oneness of Socrates, the oneness of Plato, etc. All of these exist, so the one exists. But we cannot infer that the one does not exist in a similar way; for none of the individual onenesses have this property! Plato need not, therefore, be committed to the claim that the one is not. ${ }^{57}$

However, there is another, and more intriguing, possibility. The conclusions of deduction $I I I$ are essentially just a reprise of things that have gone before in deductions $I$ and $I I$. The conclusions of deduction $I V$ are quite different. As we observed, appearances enter the plot for the first time. Deduction $I V A$ starts by establishing that the others are a plurality. Given Parmenides' own view, pluralities are not real; they are all appearances. And given that one is not, there are no unities either. So everything is just appearances. The rest of $I V A$ merely spells out the consequences. Deduction $I V B$ takes up the theme. If there are no unities, there are only pluralities; and these do not exist either. It's all appearances again. And if it's all appearances, then one can say nothing true of the form 'that something is so and so is the case' - not even something of the form 'that something appears to be so and so is the case'. And so we end up with the final spectacular nihilism: nothing is (the case).

Against Parmenides and the other Eleatics, this is a pretty good argument. Plato does not have to subscribe to the conclusion, however. Even if the others form a multitude, it does not follow that all is appearance. Plato is not committed to the view that multitudes are inherently unreal. Even if the one is not, there can still be a many; and a group of things can instantiate the form of being a manifold. The fact that something is a plurality means that it is not one. That is quite consistent with nothing else being a one either. The elements of a multitude, then, are multitudes. It's multitudes all

\footnotetext{
${ }^{57}$ Nor, as far as this argument goes, to the things that follow from it, conclusions 14 and 15 . However, we have already noted in connection with deduction $I B$ that the gluon model delivers at least one understanding of conclusion 14. And Plato might well have been happy to get away from the obvious self-refutation delivered by 15 .
} 
the way down. ${ }^{58}$

I suggest, then, that Plato's real opponents in the dialogue are the Eleatics. Deduction $I V$ employs the premise that pluralities are unreal enthymematically. It's not a premise that he subscribes to, but it makes for a powerful ad hominem argument.

\section{Deduction IC (155e-157b)}

It remains to consider the apparently anomalous appendix to Deduction $I$, $I C$. What is it doing there? In a way, this is the most puzzling feature of the deductions.

$I C$ is still about the one, and starts as follows (155e-156a):

"Let's speak of it a third time. If one is as we have described it - being both one and many and neither one nor many, and partaking of time - must it not, because it is one, sometimes partake of being, and in turn because it is not, sometimes not partake of being?"- "Necessarily." - "When it partakes, can it at that time not partake, or partake when it doesn't?"- - It cannot."- "So it partakes at one time, and doesn't partake at another; for only in this way could it partake and not partake of the same thing." "That's right." - "Isn't there, then, a definite time when it gets a share of being and when it parts from it? Or how can it at one time have and at another time not have the same thing, if it never gets and releases it?"- "In no way."

Parmenides says that he is speaking about the one 'for a third time', but unlike the second, he does not go back to the beginning, but, as is clear,

\footnotetext{
${ }^{58}$ There is a argument we noted in Deduction $I I B$ which might appear to gainsay this interpretation (159d): "In no way, then, are the others one, nor do they have any oneness in them."- "Yes, you're quite right." "So the others aren't many either; for each of them would be one part of a whole, if they were many ...' Each of a multitude of parts is one part of a whole, and so one. But this assumes that there are wholes (ones). This is perfectly acceptable in deduction $I I B$, which is carried out under the asumption that one is. The reasoning cannot be carried out in Deduction $I V$, which is based on the negation of this assumption.
} 
assumes the results of the first two deductions. The point is that if the one both is and is not, there is no time at which both are the case. At some times it is one, at some times it is the other. The next paragraph applies the same thoughts to some other categories: one and many, like and unlike, greater and lesser, equal and unequal, rest and motion.

Many commentators ${ }^{59}$ have seen this as a way of resolving the contradictions established in $I A$ and $I B$. But whatever it is, it is not that. We are taking over the results of $I A$ and $I B$. Indeed, it is conclusion 14 of $I B$ that the one is in time. But conclusion 12 of $I A$ establishes that the one is not in time. We still have this contradiction. If we tried to resolve it in the same way, we would get: there is a time when the one is in time, and a time when it is not in time - the second conjunction of which is just as contradictory. In any case, if this were the point of the deduction, it could finish here; but it continues. The conclusions of the deduction, for what it is worth, are as follows:

\footnotetext{
${ }^{59}$ E.g., Gill (1996), pp. 85-6.
} 


\begin{tabular}{|c|l|}
\hline & Deduction IC \\
\hline \hline 1. & $\begin{array}{l}\text { The one partakes of being at one time, } \\
\text { but doesn't partake at another. }\end{array}$ \\
\hline 2. & $\begin{array}{l}\text { There is a definite time where one gets } \\
\text { a share of being, and when it leaves it. }\end{array}$ \\
\hline 3. & $\begin{array}{l}\text { The one comes to be and ceases to be } \\
\text { when it gets and releases being. }\end{array}$ \\
\hline 4. & $\begin{array}{l}\text { If an object moves at one time } \\
\text { and is at rest at another, it must } \\
\text { change from one state to the other. }\end{array}$ \\
\hline 5. & $\begin{array}{l}\text { At this time, it is neither } \\
\text { in motion nor at rest. }\end{array}$ \\
\hline 6. & $\begin{array}{l}\text { There is no time at which an object } \\
\text { is neither in motion nor at rest. }\end{array}$ \\
\hline 7. & $\begin{array}{l}\text { The change occurs at an instant } \\
\text { which is not in time. }\end{array}$ \\
\hline 8. & $\begin{array}{l}\text { At the instant of change, the one } \\
\text { is neither in motion nor at rest. }\end{array}$ \\
\hline 9. & $\begin{array}{l}\text { At the instant of change, the one } \\
\text { neither is nor is not, and neither } \\
\text { comes to be nor ceases to be. }\end{array}$ \\
\hline 10. & Similarly with other states and processes. \\
\hline
\end{tabular}

When the deduction continues, it argues that if an object is in different states at different times, there must be an instant of change, which is itself outside time (156c):

"And whenever, being in motion, it comes to rest and whenever, being at rest, it changes to moving, it must itself, presumably, be in no time at all." - "How's that?"- "It won't be able to undergo being previously at rest and later in motion or being previously in motion and later at rest without changing."- - Obviously not.""Yet there is no time in which something can, simultaneously, be neither in motion nor at rest."-"Yes, you're quite right."- "Yet 
surely it doesn't change without changing."-_Hardly." - "So when does it change? For it does not change while it is at rest or in motion, or while it is in time."- "Yes, you're quite right."

Moreover, at the instant outside time, the one is neither at rest nor in motion (156d-156e):

"Is there, then, this queer thing in which it might be, just when it changes?"- "What queer thing?"- "The instant. The instant seems to signify something such that changing occurs from it to each of the two states. For a thing doesn't change from rest while rest continues, or from motion while motion continues. Rather, this queer creature, the instant, lurks between motion and restbeing in no time at all — and to it and from it the moving thing changes to resting and the resting thing changes to moving."- "It looks that way." - "And the one, if in fact it both rests and moves, could change to each state - for only in that way could it do both. But in changing, it changes at an instant, and when it changes, it would be in no time at all, and just then would be neither in motion nor at rest."- - No, it wouldn't."

The next paragraph claims that the same is true of other pairs of states, being and not being, many and one, like and unlike, equal and unequal, etc. The subject is then abruptly dropped, and Deduction II A commences.

What to make of this? The point, it is clear, is to establish something about an instant of change, outside time; and prima facie this something is that at this instant, neither of the pairs of states, prior and posterior, is realised. But wait a minute. Weren't these states contradictories: to be in rest is not to be an motion, and vice versa? So to be in neither of them is itself a contradiction. The instant, then, is a contradictory creature. Plato is careful to say that it is only at the same time that something cannot, e.g., both be and not be (155e, my italics): "When it partakes, can it at that time not partake, or partake when it doesn't?"- "It cannot." The instant is outside time.

It might be suggested that rest and motion, etc., are not contradictories, but contraries. The trouble with this suggestion is that the opposing pairs 
are not always specified independently (rest/motion, same/different), but are frequently specified using negation. Thus, we have in Deduction $I$ : is [is not] a whole $(I A, 2 ; I B, 3)$, has [has not] a beginning $(I A, 3 ; I B, 6)$, is [is not] in itself $(I A, 6 ; I B, 8)$, is [is not] in time $(I A, 12 ; I B, 14)$. And negation is a contradictory-forming operator. To say that something has neither of a pair of contradictory properties is itself contradictory.

Plato is blunt about the matter concerning one such pair: is [is not]. Just after the last passage quoted, Parmenides says (157a, my italics):

"Is it so with the other changes too? Whenever the one changes from being to ceasing-to-be, or from not-being to coming-to-be, isn't it then between states of motion and rest? And then it neither is nor is not, and neither comes nor ceases to be."

Look at the italicised claim. It says that the one is not, and it is not the case that it is not. Even without the law of double negation (which would convert this into 'the one is not and is'), this is a flat contradiction.

There is a general point here: to say that something is neither $\neg A$ nor $A$ is to say $\neg(\neg A \vee A)$, and by De Morgan's law, ${ }^{60}$ this is equivalent to $A \wedge \neg A$. To be in a state of neither is to be in a state of both.

So what is going on here? $I A$ and $I B$ have established that the one has contradictory properties. Plato expects objections. IC starts with a natural one: the one is not really contradictory, since the contradictions may be defused by an appeal to time. The rest of the deduction then shows that, even if one appeals to time, one still ends up with a contradictory object: the instant.

And now, crucially: Plato puts in an appendix to Deduction $I$, but not to the others; why not? He has no reason to. If I am right, the appendix is a reply to an objection to the effect contradictions can be avoided by appealing to time. He does not have to reply to this objection more than once.

\footnotetext{
${ }^{60}$ Which is valid in most paraconsistent logics. There is nothing about dialetheism that renders it invalid.
} 


\section{Putting Things into Perspective}

So much for the commentary. Let me now step back and put the whole thing into perspective. According to the interpretation of the Parmenides I am mooting, things look like this. At some stage after Plato had formulated his theory of forms, he came to see that there were problems with it, and especially with the notion of participation. Maybe these occurred to him, himself; more likely, I would guess, they were put to him by others. The fact that he has Parmenides put the arguments might suggest that it was, perhaps, by some Eleatics. This is the dialogue he wrote about the problems.

In the first part of the dialogue, the problems are expounded. Plato is not sure of the exact solution, though he wants to see if they can be answered. The key to a solution, it occurs to him, could be in the contradictory nature of the forms. A satisfactory solution can not just, of course, simply accept the theory and the contradictory conclusions posed by the objections. That would be $a d$ hoc and entirely unsatisfactory. ${ }^{61}$ There has to be a principled and unified account of participation that solves the worries. Still, he knows that the possibility of contradictory forms is likely to meet opposition. This is what the second part of the dialogue is about.

He sets things up at the beginning of the dialogue by getting the young (and naive) Socrates to contrast the world of the forms and the world of appearances, and claim that even if the latter are contradictory, the forms are not. This is what gets knocked down in the second part of the dialogue.

Deductions $I A$ and $I B$ establish that the form of unity is contradictory. The conclusion is liable to force a substantial balk in members of Plato's audience; the arguments of Deduction $I$ are therefore the most extensive and detailed. And it doesn't matter if not all the arguments to contradiction work, as long as some of the arguments of the barrage do. At the end of Deduction $I$, Plato imagines an opponent objecting by suggesting that the contradictions may be resolved by appealing to time. IC shows that this objection will not work.

For the solution to work, there must be nothing special about the contradictory nature of the form of unity. So Deduction $I I$ establishes that the

\footnotetext{
${ }^{61}$ See Priest (1998), Objections 3 and 4, and more generally, Priest (2006), chs. 7, 8 .
} 
other forms have contradictory properties too.

He knows that proponents of the PNC will still want to object; they may do so by denying the assumption of deductions $I$ and $I I$ : that Plato's one exists. So we have $I I I$ and $I V$. These show that the consequences of its not existing (with contradictory properties) are just as bad - or even worse. This was the method reputed to have been used by Zeno in defence of Parmenides. So Plato brings Zeno into the dialogue, and has him spell out the method right at the start $(128 \mathrm{~d})$ :

"[M]y book speaks against those who assert the many and pays them back in kind with something for good measure, since it aims to make clear that their hypothesis, if one is many, would, if someone examined the matter thoroughly, suffer consequences even more absurd than those suffered by the hypothesis of its being one."

By the end of the dialogue, the contradictory nature of the forms is defended, and the dialogue ends.

What was left for Plato to do to finish this defence of the theory of forms - the dialogue obviously ends in mid air - was to use the possibility that the forms are contradictory to articulate a principled account of the notion of participation which answered the objections to the theory of forms he had found. There are clearly thoughts that might feed into the project at places in the deductions, as we have seen; but he never succeeded in doing this - at least to judge by his extant dialogues. Maybe, like a particularly elusive form, he perceived it dimly, but was never able to get it into exact focus. As he has Parmenides say (135a-135b):

"Only a very gifted man can come to know that for each thing there is some kind, a being by itself; but only a prodigy more remarkable still will discover that and be able to teach someone else who has sifted through all these difficulties thoroughly and critically for himself."

At any rate, over two millennia later, when the Aristotle-inspired horror contradictionis is finally beginning to fade, Plato's project can now be brought to fruition. 
Let me end by returning to the very first oddity of the dialogue that I noted in the introduction. Why does Plato make Parmenides the driver of the dialogue? One of the things centrally under attack in the dialogue, as I have interpreted it, is the PNC. Parmenides was the first person to formulate and advocate the Principle: ${ }^{62}$

Never will this prevail, that what is not is;

restrain your thought from this road of inquiry

and do not let custom, based on experience, force you along this

road,

directing unobservant eye and echoing ear

and tongue; but judge by reason the battle-hardened proof

which I have spoken.

Indeed, the Principle is the cornerstone of the view that the historical Parmenides articulated and defended. Ostensibly, the Parmenides is a critique of Plato (in the form of Socrates) by Parmenides. But in reality, the tables are actually turned, and the dialogue is a critique of Parmenides by Plato, since it attacks this cornerstone of his view-indeed, if deduction $I V$ is ad hominem, then Plato is thinking of Eleatics as his real opponents in the dialogue. ${ }^{63}$ Moreover, in this critique, Plato not only commandeers Parmenides' argument as part of his own (in $I A$ ), but mischievously puts the whole argument in Parmenides' own mouth - an act of chutzpah perhaps unique in Western philosophy!

\section{References}

[1] Allen, R. E. (1983), Plato's Parmenides, Oxford: Blackwell.

[2] Bacon, J. (1995), Universals and Property Instances: the Alphabet of Being, Oxford: Blackwell.

\footnotetext{
${ }^{62}$ Barnes (1987), p. $133 \mathrm{f}$.

${ }^{63}$ For what it is worth, after Socrates' death, Plato studied with the Parmenidean Hermogenes, according to Diogenes Laertius, Lives of Eminent Philosophers, III, 6.
} 
[3] Barnes, J. (1987), Early Greek Philosophy, Harmondsworth: Penguin.

[4] Cherniss, H. (1957), 'The Relation of the Timaeus to Plato's Later Dialogues', American Journal of Philology 78: 225-266.

[5] Cornford, F. M. (1939), Plato and the Parmenides, London: Routledge and Kegan Paul.

[6] Dodds, E. R. (1928), 'The Parmenides of Plato and the Origin of the Neo-Platonic "One", Classical Quarterly 22: 129-42.

[7] Frances, B. (1996), 'Plato's Response to the Third Man Argument in the Paradoxical Exercise of the Parmenides', Ancient Philosophy 16: 47-64.

[8] Gill, M. L. (1996), 'Introduction', pp. 1-116 of Gill and Ryan (1996).

[9] Gill, M. L., and Ryan, P. (1996), Plato: Parmenides, Indianapolis, IN: Hackett Publishing Co.

[10] Haldane, E. S., and Simpson, F. H. (transs.) (1995), Lectures on the History of Philosophy, Vol. 2: Plato and the Platonists, Lincoln, NE: University of Nebraska Press.

[11] Hamilton, E., and Cairns, H. (1961), The Collected Dialogues of Plato, Princeton, NJ: Princeton University Press.

[12] Meinwald, C. C. (1991), Plato's Parmenides, Oxford: Oxford University Press.

[13] Miller, M. H. (1986), Plato's Parmenides: The Conversion of the Soul, Princeton, NJ: Princeton University Press.

[14] Pemberton, H. J. (1984), Plato's Parmenides: the Critical Moment for Socrates, Darby, PA: Norwood Editions.

[15] Petersen, S. (1996), 'Plato's Parmenides: a Principle of Interpretation, and Seven Arguments', Journal of the History of Philosophy 34: 167-92. 
[16] Priest, G. (1987), In Contradiction: a Study of the Transconsistent, Dordrecht: Martinus Nijhoff. Second edition, Oxford: Oxford University Press, 2006.

[17] Priest, G. (1995), Beyond the Limits of Thought, Cambridge: Cambridge University Press. Second edition, Oxford: Oxford University Press, 2002.

[18] Priest, G. (1998), 'What's so Bad about Contradictions?', Journal of Philosophy 95: 410-26. Reprinted as ch. 1 of G. Priest, J. Beall and B. Armour-Garb (eds.), The Law of Non-Contradiction: New Philosophical Essays, Oxford: Oxford University Press, 2004.

[19] Priest, G. (2005), Towards Non-Being, Oxford: Oxford University Press.

[20] Priest, G. (2006), Doubt Truth to be a Liar, Oxford: Oxford University Press.

[21] Priest, G. (201+), One, Oxford: Oxford University Press, forthcoming.

[22] Priest, G., and Tanaka, K. (2009), 'Paraconsistent Logic', Stanford Encyclopedia of Philosophy, http://plato.stanford.edu/entries/logicparaconsistent/ (accessed January 2013).

[23] Rickless, S. (1998), 'How Parmenides Saved the Theory of Forms', Philosophical Review 107: 501-54.

[24] Rickless, S. (2007), 'Plato's Parmenides', Stanford Encyclopedia of Philosophy, http://plato.stanford.edu/entries/parmenides/ (accessed May 2008).

[25] Scolnicov, S. (2003), Plato's Parmenides, Berkeley, CA: University of California Press. 